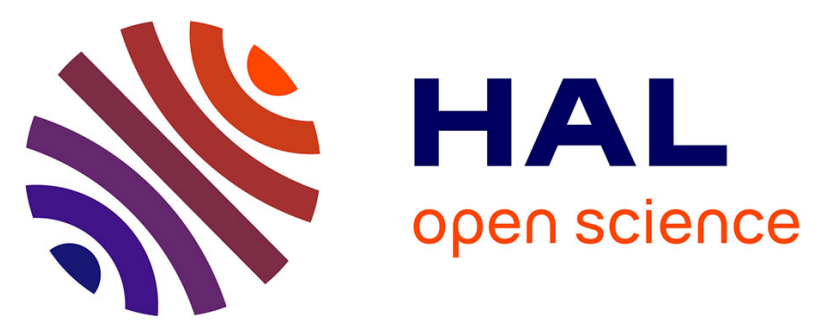

\title{
Novel insights into the metabolic and biochemical underpinnings assisting dry-season survival in female malaria mosquitoes of the Anopheles gambiae complex.
}

Kévin Hidalgo, Karine Mouline, Wadaka Mamai, Natacha Foucreau, K. Rock Dabiré, Alain Bouchereau, Frédéric Simard, D Renault

\section{To cite this version:}

Kévin Hidalgo, Karine Mouline, Wadaka Mamai, Natacha Foucreau, K. Rock Dabiré, et al.. Novel insights into the metabolic and biochemical underpinnings assisting dry-season survival in female malaria mosquitoes of the Anopheles gambiae complex.. Journal of Insect Physiology, 2014, 70 (11), pp.102-116. 10.1016/j.jinsphys.2014.07.003 . hal-01072208

\author{
HAL Id: hal-01072208 \\ https://hal.science/hal-01072208
}

Submitted on 7 Oct 2014

HAL is a multi-disciplinary open access archive for the deposit and dissemination of scientific research documents, whether they are published or not. The documents may come from teaching and research institutions in France or abroad, or from public or private research centers.
L'archive ouverte pluridisciplinaire HAL, est destinée au dépôt et à la diffusion de documents scientifiques de niveau recherche, publiés ou non, émanant des établissements d'enseignement et de recherche français ou étrangers, des laboratoires publics ou privés. 


\title{
Novel insights into the metabolic and biochemical underpinnings assisting dry-season survival in female malaria mosquitoes of the Anopheles gambiaecomplex
}

\author{
K. Hidalgo, b, * 1 \\ K. Mouline ${ }^{\mathrm{b}, \mathrm{c}, 1}$ \\ W. Mamaib, c \\ N. Foucreau ${ }^{\mathrm{d}}$ \\ K.R. Dabiréc \\ A. Bouchereaue \\ F. Simard ${ }^{\mathrm{b}}$ \\ D. Renaulta
}

kevin.hidalgo@live.fr

aUniversité de Rennes 1, UMR CNRS 6553 Ecobio, Campus de Beaulieu, 263 Avenue du Général Leclerc, CS 74205, 35042 Rennes Cedex, France

bInstitut de Recherche pour le Développement (IRD), UMR IRD 224-CNRS 5290-Université de Montpellier 1, Université de Montpellier 2 MIVEGEC, 911 Avenue Agropolis, BP 64501, 34394 Montpellier cedex 5, France

'Institut de Recherche en Sciences de la Santé (IRSS), Direction Régionale de l'Ouest (DRO), 399 Avenue de la Liberté, o1 BP 545, Bobo-Dioulasso, Burkina Faso

dUniversité Claude Bernard Lyon 1, UMR CNRS 5023 LEHNA, 43 Bd du 11 Novembre 1918, 69622 Villeurbanne Cedex, France

eUniversité de Rennes 1, UMR INRA IGEPP, Campus de Beaulieu, 263 Avenue du Général Leclerc, CS 74205, 35042 Rennes Cedex, France

"Corresponding author at: Université de Rennes 1, UMR CNRS 6553 Ecobio, Campus de Beaulieu, 263 Avenue du Général Leclerc, CS 74205, 35042 Rennes Cedex, France. Tel.: +33 2232366 27; fax: +33 223235046.

${ }^{1}$ K.H. and K.M. contributed equally to this work. 


\section{Abstract}

The mechanisms by which Anopheles gambiae mosquitoes survive the desiccating conditions of the dry season in Africa and are able to readily transmit malaria soon after the rains start remain largely unknown. The desiccation tolerance and resistance of female An. gambiae M and S reared in contrasting environmental conditions reflecting the onset of dry season ("ods") and the rainy season ("rs") was determined by monitoring their survival and body water loss in response to low relative humidity. Furthermore, we investigated the degree to which the physiology of 1-h and 24-h-old females is altered at"ods" by examining and comparing their quantitative metabotypes and proteotypes with conspecifics exposed to "rs" conditions. Results showed that distinct biochemical rearrangements occurred soon after emergence in female mosquitoes that enhance survival and limit water loss under dry conditions. In particular, three amino acids (phenylalanine, tyrosine, and valine) playing a pivotal role in cuticle permeability decreased significantly from the 1-h to $24-\mathrm{h}-$ old females, regardless of the experimental conditions. However, these amino acids were present in higher amounts in 1-h-old female An. gambiae M reared under "ods" whereas no such seasonal difference was reported in S ones. Together with the 1.28- to 2.84-fold increased expression of cuticular proteins 70 and 117 , our data suggests that cuticle composition, rigidity and permeability were adjusted at "ods". Increased expression of enzymes involved in glycogenolytic and proteolytic processes were found in both forms at "ods". Moreover, 1-h-old S forms were characterised by elevated amounts of glycogen phosphorylase, isocitrate dehydrogenase, and citrate synthase, suggesting an increase of energetic demand in these females at "ods".

Abbreviations: TCA, tricarboxylic acid cycle; RH, relative humidity; "rs", rainy season; "ods”, onset of the dry season; LDA, linear discriminant analysis;LD1, first axis of the linear discriminant analysis; LD2, second axis of the linear discriminant analysis

Keywords: Body water; Desiccation; Metabolic fingerprint; Proteomics; RR-2 cuticular protein; Tricarboxylic acid cycle enzyme

\section{Introduction}

Dry savannahs of West Africa are characterised by the occurrence of two contrasting environmental seasons: a dry season, with important daily fluctuations in air temperature and significant decrease of the relative humidity, and a rainy season, during which temperature fluctuations flatten and water ponds are refilled. The alternation of these two distinct seasons has a strong impact on the life cycle of many insect species, including mosquitoes (Fontenille et al., 1997; Touré et al., 1998). In particular, malarial mosquito densities have been found to follow the pace of breeding-site dynamics (i.e., water ponds). Hence, the pattern of malaria transmission is highly seasonal, and transmission mainly occurs during the rainy season when mosquito densities are the highest (Lemasson et al., 1997).

Water availability represents an important environmental driver setting the seasonal phenology of mosquito species. Mosquitoes in the Anopheles gambiaecomplex, especially the $\mathrm{M}$ and $\mathrm{S}$ molecular forms of An. gambiae sensu stricto, are the major vectors of malaria in the Sub-Saharan Africa (Fontenille and Simard, 2004). ${ }^{2}$ To date, it is not known how malaria vectors survive the climatic dry-season conditions, and are able to readily achieve explosive population growth as soon as the rains start again (Lehmann et al., 2010; Simard et al., 2000). Of note, in areas where there are large-scale agricultural irrigation schemes or dams, and thus permanent water ponds, the M molecular form of $A n$. gambiae s.s. breeds all year long, thereby extending malaria transmission into the dry season (Baldet et al., 2003; Touré et al., 1998). Interestingly, the genetically distinct $\mathrm{S}$ form of An. gambiae - assumed to be the ancestral form - is not found in such settings (Gimonneau et al., 2012). Population densities of the $S$ form typically drop below the sampling detection limit soon after the onset of the dry season (Adamou et al., 2011; Lehmann et al., 2010), precluding field investigations of the mechanisms underlying dry-season survival strategy in this mosquito. Meanwhile, investigations of population genetics ruled out severe demographic bottlenecks in areas with strong seasonal fluctuations on the abundance of these mosquitoes. These results suggest that a significant number of adult specimens survive locally during the dry season (Simard et al., 2000; Taylor et al., 1993), as the pre-imaginal stages (eggs, larvae and pupae) are not able to survive without water (Koenraadt et al., 2003; Minakawa et al., 2001). Hence, it was generally proposed that mosquito populations can be maintained in large numbers during the dry season via aestivating females that do not reproduce (Holstein, 1954; Lehmann et al., 2010; Omer and Cloudsley-Thompson, 1970), and thus survive the challenging desiccating environmental conditions.

Desiccation represents a significant environmental stress for insects and can drive their geographical distributions (Chown and Nicolson, 2004), locomotor activities (Hoffmann and Parsons, 1993), reproduction (Benoit et al., 2010), and longevity (Hoffmann and
Harshman, 1999). In insects, body water can be lost by excretion from oral and anal openings, respiratory gas exchange, and cuticular transpiration. Cuticular transpiration represents an important route of body water loss, and can account for up to $80 \%$ of the total body water loss in quiescent insects (Quinlan and Gibbs, 2006). Interestingly, body water loss is significantly minimised in insects inhabiting xeric environments: among other mechanisms, discontinuous (or cyclic) gas exchange, and decreased cuticular permeability viaalteration of the biochemical composition are elaborated in such insects to limit body water loss (Chown et al., 2011).

A primary barrier to cuticular water loss in insects is cuticular lipids, which confer most of the waterproofing in several species (Hadley, 1994). However, no direct relationship between body water loss, and the qualitative and/or quantitative nature of surface lipids of the cuticle was observed among specimens of Drosophila sp. (Diptera, Drosophilidae) from distinct habitats, or among specimens of Drosophilamojavensis acclimated to distinct thermal conditions (Gibbs et al., 1998, 2003). Other than lipids, the chemical composition of the cuticle includes sugars, proteins and peptides rich in amino acids such as alanine, arginine, glycine, proline, and valine (Neville, 1975; Stankiewicz et al., 1996). Among amino acids, aromatic ones, such as phenylalanine, tryptophan, and tyrosine, also represent important components of the exoskeleton. Depending on the amounts in which they are present, these aromatic amino acids can influence the hydrophobicity of the insect cuticle (Andersen, 1979). In addition, the possible involvement of cuticular proteins in water regulation has recently been reemphasised (Benoit et al., 2010), but this assumption remains to be documented conclusively. Lastly, dehydration can be tolerated by the accumulation of compatible solutes, including polyols, sugars, and amino acids (Yancey, 2005). In particular, polyols and sugars can efficiently replace the water that surrounds membranes and proteins (see the "water-replacement hypothesis", (Crowe, 1992)).

In the present study, we explored the physiological and biochemical adjustments of freshly emerged $\mathrm{M}$ and $\mathrm{S}$ forms of $A n$. gambiae s.s. in response to developmental acclimation to environmental conditions typical of the rainy ("rs") and the onset of the dry ("ods") seasons in Burkina-Faso. We assumed that developmental plasticity and acclimation play pivotal roles in augmenting the survival capabilities of mosquitoes during the dry season. We hypothesised that both molecular forms would display altered seasonal phenotypes between the dry and rainy seasons. We expected (i) distinct levels of resistance (i.e., reduced body water loss) and tolerance (i.e., survival probability) to desiccation between "rs"- and "ods"-reared mosquitoes in both molecular forms, (ii) physiological and biochemical rearrangements elicited by desiccation, including the accumulation of compatible solutes, changes in the expression level of structural proteins involved in the chemical composition of the cuticle, and (iii) increased expression of the proteins 
involved in the energetic metabolism (i.e., TCA cycle) in "ods"-reared mosquitoes demonstrating the higher energetic demands (synthesis of compatible solutes, migration to more favourable microhabitats) imposed by the arrival of the dry season. We also assumed that because of the distinct phenology observed between $\mathrm{M}$ and $\mathrm{S}$ forms in the dry savannahs of West-Africa, these two molecular forms should express distinct phenotypes reflecting the different survival strategies involved by adults during the dry season. In particular, the $\mathrm{M}$ form should be characterised by a higher desiccation resistance than the $\mathrm{S}$ form, whereas signs of increased energy production supporting migratory activity should be observed in the $\mathrm{S}$ form. In this work, the desiccation resistance of female An. gambiae $\mathrm{M}$ and $\mathrm{S}$ was determined by monitoring their body water loss and survival in contrasting environmental conditions. Further, the quantitative metabotypes and proteotypes were measured in 1-h and 24-h-old adult female mosquitoes. Both metabolomics and proteomics were used to emphasise some of the biochemical adjustments leading to an alternate phenotype during the dry season in these mosquitoes.

\section{Materials and methods}

\subsection{Mosquitoes}

\subsubsection{Source-mosquito colonies}

Experiments were conducted using two An. gambiae colonies established from gravid $\mathrm{M}$ and $\mathrm{S}$ females collected in Burkina-Faso from human dwellings of Bama $\left(11^{\circ} 23^{\prime} \mathrm{N}, 04^{\circ} 24^{\prime} \mathrm{W}\right)$ and Soumousso $\left(11^{\circ} \mathrm{O} 1^{\prime} \mathrm{N}\right.$, $\mathrm{O}^{\circ}{ }^{\circ} 2^{\prime} \mathrm{W}$ ), respectively (see Mouline et al., 2012 for the entomological context of these localities). The colonies were maintained at the Institut de Recherche en Sciences de la Santé (IRSS) in Bobo-Dioulasso under controlled conditions $\left(27 \pm 1^{\circ} \mathrm{C}, 80 \pm 10 \%\right.$ relative humidity with a
$12 \mathrm{~h}: 12 \mathrm{~h} \mathrm{~L}: \mathrm{D}$ cycle), and routinely blood fed on restrained rabbits prior to being used for the experiments. The mosquito colonies were checked monthly using PCR methods (Santolamazza et al., 2008) to ensure the absence of hybrid contamination between the $\mathrm{M}$ and $\mathrm{S}$ molecular forms of An. gambiae.

\subsubsection{Experimental conditions}

Mosquitoes were reared, from eggs to adults, in programmable climatic chambers (Sanyo MLR 315H, Sanyo Electric Co., Osaka, Japan, $N=2$ climatic chambers for each experimental condition). Temperature and relative humidity ( $\mathrm{RH})$ cycles were programmed into the climatic chambers using climatic data hourly recorded from the village of Bama with a Vantage Pro2 weather monitoring station (Weatherlink; Davis Instruments, Hayward, CA, USA) from August 1st to 31th 2010 (i.e., during the rainy season, hereafter referred to as "rs" conditions) and from December 1st to 31th 2010 (i.e., at the onset of the dry season, hereafter referred to as "ods" conditions). Hourly recorded temperatures and $\mathrm{RH}$ from the entire months were averaged, and then a 12-step cycle was designed to reproduce as closely as possible the natural daily climatic fluctuation of "rs" and "ods" in the climatic chambers. Temperature $\left({ }^{\circ} \mathrm{C}\right)$ and relative humidity $(\mathrm{RH})$ were tightly monitored inside each climatic chamber using MicroLog Pro monitors (EC750, Davis Instruments, Hayward, CA, USA) (Fig. 1), and desiccant (Silica gel Chameleon(C) was used to prevent humidity bursts in the "ods" conditions. Variation in photoperiod is greatly reduced in the tropics (ca.2 1-h 15 min day length variation between the solstices in Bobo-Dioulasso, Burkina-Faso); therefore, the same photoperiod was used for the "rs" and "ods" conditions (12:12 h, L:D cycle).

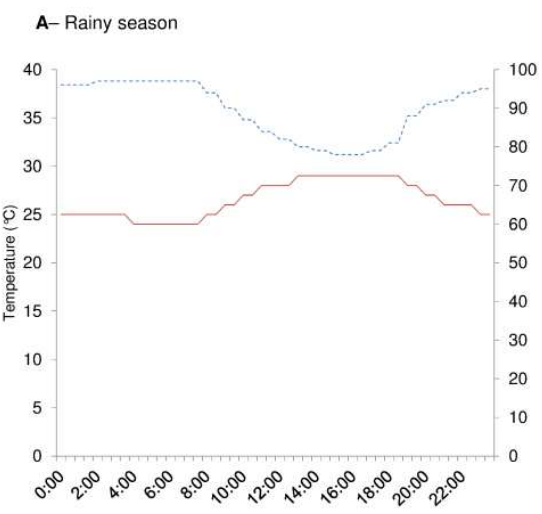

B- Onset of the dry season

Daily time (hour)

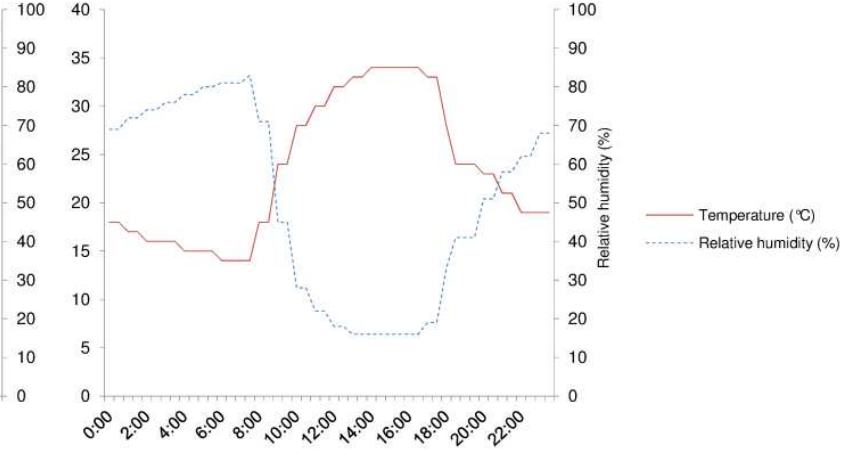

$$
\text { hour) }
$$

Fig. 1 Daily temperature $\left({ }^{\circ} \mathrm{C}\right.$ - red line) and relative humidity (\% - dashed blue line) used to simulate the natural climatic variations within the climatic chambers: (A) rainy season ("rs"), and (B) onset of the dry season ("ods"). The L:D cycle was set at $12 \mathrm{~h}: 12 \mathrm{~h}$ in both conditions. (For interpretation of the references to colour in this figure legend, the reader is referred to the web version of this article.)

\subsubsection{Insect rearing}

Mosquitoes were reared in three independent sessions from fresh batches of eggs obtained from more than 50 caged females for each molecular form. Two batches of eggs were merged to achieve large sample sizes and synchronous hatching for each session. Females in the first two sessions were used for metabolomic and proteomic assays, and females from the third batch were used for desiccation tolerance assays (i.e., body water content and survival). For each environmental chamber $(N=4)$, the experimental conditions ("rs", "ods") were switched between the sessions.

Upon collection in the colony cages, mosquito eggs were directly transferred into plastic trays $(30 \mathrm{~cm} \times 20.5 \mathrm{~cm} \times 6.5 \mathrm{~cm})$ containing deionised water, and immediately exposed to "rs" or "ods" conditions in the climatic chambers. After hatching, first instar larvae were quickly transferred into new plastic trays at an optimal rearing density of 200 larvae per tray. Fifteen trays (i.e. 3000 larvae) were used for each mosquito colony and each experimental condition ("rs", "ods"). Every day, the position of the trays was randomly alternated to avoid positional effects within the incubators. The larvae were fed daily ad libitum with ground fish food (Tetramin $囚$ ) until pupation. Pupae were then collected and put into a plastic cup (diameter $7 \mathrm{~cm} \times$ height $8.5 \mathrm{~cm}$ ) filled with $10 \mathrm{ml}$ of deionised water, and covered with a fine net to prevent emerging adults from escaping. Males were discarded upon emergence, and only females were used in further experiments. The females were deprived of food throughout the experiments to control for any possible physiological difference that would have resulted from differential feeding among individuals.

Upon emergence, adult females were randomly assigned to one of four experimental treatments (1-h or 24-h exposure to the "rs" or "ods" conditions). Adult emergence was checked every hour, and newly emerged adults were immediately snap frozen, and stored at $80{ }^{\circ} \mathrm{C}$ for further metabolomic and proteomic assays (i.e. o to 1-h-old mosquitoes, hereafter named 1-h-old mosquitoes). The remaining females were maintained in the plastic cups in the climatic chambers and exposed to "rs" or "ods" conditions for an additional $23 \mathrm{~h}$ period (i.e., 23 to 24-h-old mosquitoes, hereafter named 24-h-old mosquitoes), 
collected and stored for further metabolomic assays. Pools of $5^{-6}$ females from the two first rearing sessions were collected for each experimental condition for the metabolomic assays, and pools of 30 females were used for the proteomic assays.

\subsection{Desiccation tolerance of female mosquitoes 2.2.1 Changes in body water content and dry mass}

Fresh and dry masses were assessed using a microbalance (Sartorius SE2, $d=1 \mu \mathrm{g}$ ) in a subset of freshly formed pupae and 1-h-old females of both molecular forms reared under "rs" or "ods" conditions. Body water content was calculated for each female as the difference between fresh and dry mass, and expressed in mg per mg of fresh mass. The gender of the pupae was determined by morphological observation under a binocular (x40, Leica S6D), and female pupae were gently moved on an absorbent paper using a small brush to remove external water before they were weighted. Eighty-seven pupae and 140 freshly emerged females (1-h-old) were used to conduct this assay.

To examine desiccation tolerance of both molecular forms, we used 24-h-old females from both "rs" and "ods" settings. These females were provided only with cotton balls soaked with water upon emergence. This access to water was removed after $12 \mathrm{~h}$, as differential water uptake among the mosquitoes prior to the experiments would have contributed to experimental variation. Then, the 24-h-old females were put into plastic cups covered with nets. The cups were placed into large plastic boxes filled with desiccant (Silica gel Chameleon(C), lowering RH inside the cup to $5-7 \%$ as measured by a T/H recorder MSR145 (MSR Electronics, GmBH, Switzerland). The boxes containing the cups were stored in a climatic chamber at $27^{\circ} \mathrm{C}$. Mosquitoes were sampled $0,3,6$, 9, and $12 \mathrm{~h}$ after the females were exposed to these "low RH” experimental conditions (i.e., female mosquitoes were sampled when they were $24-\mathrm{h}, 27-\mathrm{h}, 30-\mathrm{h}, 33-\mathrm{h}$ and $36-\mathrm{h}$ old), in order to monitor changes in body water content over time. After each collection, females were quickly chloroform-anesthetised for 30_s prior to measuring their fresh mass (Sartorius $\mathrm{SE} 2, d=1 \mu \mathrm{g}$ ). Then, all specimens were dried for three days in an incubator at $60^{\circ} \mathrm{C}$, allowing the measurement of the dry mass and body water content for each female. A total of 611 female mosquitoes were used to conduct this assay.

\subsubsection{Survival}

Survival under desiccating conditions was assessed in females of both the $\mathrm{M}$ and $\mathrm{S}$ molecular forms reared under "rs" and "ods" environmental conditions, using previously described protocols (Fouet et al., 2012; Gray et al., 2009). Twenty-four hour old females were supplied with water for the first $12 \mathrm{~h}$, and were individually placed into plastic vials $(28.5 \mathrm{~mm}$ diameter $\times 95 \mathrm{~mm}$ height) filled with $3 \mathrm{~cm}$ of desiccant (Silica gel Chameleon(C), a piece of cotton to avoid the direct contact between the mosquito and the desiccant, and sealed with a plastic film (Parafilm(C). The sealed vials were stored at $27^{\circ} \mathrm{C}$ into a climatic chamber. The relative humidity inside each vial dropped to $5-7 \%$ within $2-3 \mathrm{~h}$ from the start of the experiment. The same experimental conditions were used for the controls, except the RH which was set to $80 \%$. In all experimental conditions, female survival was assessed hourly by observing the mosquitoes and the specimens were considered dead when they could no longer stand on their legs.

\subsection{Metabolic fingerprinting}

Metabolic fingerprinting was conducted on the 1-h and 24-h-old females of both $\mathrm{M}$ and $\mathrm{S}$ forms of An. gambiae reared under "rs" and "ods" conditions that were preserved at - $-80^{\circ} \mathrm{C}$. Each sample consisted of a pool of 5-6 females to achieve a minimum sample dry mass of $1 \mathrm{mg}$. For each experimental condition and for each molecular form, 5-9 replicates were used for metabolic fingerprinting, resulting in a total of 54 samples.
Mosquitoes were freeze-dried (Lyovac ${ }^{\mathrm{TM}} \mathrm{GT} 3$ ) for $72 \mathrm{~h}$. Dry mass was measured for each sample using a micro-balance (Mettler Toledo $\mathrm{GmbH}(\mathrm{C}$, Greinfense, Switzerland, $d=1 \mu \mathrm{g}$ ). A $1000 \mu \mathrm{L}$ volume of methanol-_chloroform (2:1, v:v) solution was added to each sample and further homogenised with $3 \mathrm{~mm}$ tungsten beads at $30 \mathrm{~Hz}$ for $1.5 \mathrm{~min}$ (Retsch ${ }^{\mathrm{TM}}$ MM301, bead-beating, Retsch GbmH, Haan, Germany). A volume of $500 \mu \mathrm{L}$ of ultrapure water was added (final methanolchloroformwater solution 2:1:2, v:v:v), and the samples were further homogenised using a vortex. Samples were then centrifuged at $4000 \mathrm{~g}$ for $10 \mathrm{~min}$ at $4{ }^{\circ} \mathrm{C}$. A $600 \mu \mathrm{L}$ aliquot of the upper aqueous phase, which contained amino acids and sugars, was transferred into a clean microtube and vacuum-dried (Speed Vac Concentrator, Genevac Ltd., Ipswitch, England). A volume of $600 \mu \mathrm{L}$ of ultrapure water was added to the residual, and samples were stored at $-=80^{\circ} \mathrm{C}$ before being used for the quantification of amino acids and sugars.

\subsubsection{Circulating amino acid content}

A $20 \mu \mathrm{L}$ volume of each sample extract was diluted in $60 \mu \mathrm{L}$ of ultrapure water, from which $5 \mu \mathrm{L}$ were used for amino acid derivatisation according to the AccQTag ultra derivatisation kit protocol (Waters Corporation, Milford, MA, USA). A volume of $1 \mu \mathrm{L}$ of the derivatisation mix was used for amino acid analysis. We used an Acquity UPLC $®$ system (Waters Corporation, Milford, MA, USA) equipped with an Acquity UPLC $®$ BEH C18 $1.7 \mu \mathrm{m} 2.1 \times 100 \mathrm{~mm}$ column heated at $55{ }^{\circ} \mathrm{C}$, as described by (Renault et al., 2010). The derivatised amino acids were detected at $260 \mathrm{~nm}$ using a photo diode-array detector. Peaks were identified according to their retention time compared with commercial standards, and quantified by comparison with the individual external standards of each amino acid (Renault et al., 2010). The amino acid amounts were expressed in nmoles per mg of dry mass.

\subsubsection{Sugar content}

Sugars were quantified by gas chromatography coupled with mass spectrometry (GC-MS). A $50 \mu \mathrm{L}$ volume of each sample extract was transferred into a glass vial and vacuum-dried. The residuals were resuspended in $50 \mu \mathrm{L}$ of freshly prepared methoxyamine hydrochloride (Sigma-Aldrich, St. Louis, MO, USA) in pyridine (20 mg mL-1) prior to incubation under orbital shaking at $30{ }^{\circ} \mathrm{C}$ for $90 \mathrm{~min}$. Following incubation, a $50 \mu \mathrm{L}$ volume of N-methyl-N-(trimethylsilyl) trifluoroacetamide (MSTFA) was added, and derivatisation was conducted overnight at $37^{\circ} \mathrm{C}$. The GC-MS system consisted of a TriPlus autosampler, a Trace GC Ultra chromatograph and a Trace DSQII quadrupole mass spectrometer (Thermo Fischer Scientific Inc, Waltham, MA, USA). The injector temperature was held at $260^{\circ} \mathrm{C}$. The oven temperature remained at $70{ }^{\circ} \mathrm{C}$ for 4 min after the injection, and then increased at a rate of $5{ }^{\circ} \mathrm{C} \mathrm{min}^{-1}$ until it reached $300{ }^{\circ} \mathrm{C}$, where it remained for $10 \mathrm{~min}$. A $30 \mathrm{~m}$ fused silica column (TR5 MS, I.D. $0.25 \mathrm{~mm}$, 95\% dimethyl siloxane, $5 \%$ phenyl polysilphenylene-siloxane) was used with helium as the carrier gas at a rate of $1 \mathrm{~mL} \mathrm{~min}^{-1}$. One microlitre of each sample was injected using the split mode (25:1). MS detection was achieved using electronic impact (EI). The temperature of the ion source and MS transfer line were set to $260^{\circ} \mathrm{C}$. All of the samples were run under the SIM mode (electron energy: $70 \mathrm{eV})$. The GC-MS peaks were accurately annotated using both mass spectra (two specific ions), and a retention index specific to each compound. Randomised sample sequences were established for the sample injection. Chromatograms were deconvoluted using XCalibur v2.o.7. Standard samples consisting of the pure reference compounds (arabinose, fructose, galactose, glucose, ribose and trehalose) at 100, 200, 300, 500 and $1000 \mu \mathrm{M}$ concentrations were run, and the metabolite levels were quantified using the quadratic calibration curves for each reference compound.

\subsection{Proteomic assays}

Proteomic assays were conducted on pools of 30 females and only 1-h-old females were used. The samples were delivered to the proteomics 
department of Applied Biomics (http://www.appliedbiomics.com, Applied Biomics, Inc. Hayward, CA, USA) for processing.

\subsubsection{Protein extraction procedure}

For each sample, proteins were extracted using 2-D cell-lysis buffer (30 mM Tris- $\mathrm{HCl}$, pH 8.8, containing $7 \mathrm{M}$ urea, $2 \mathrm{M}$ thiourea, and $4 \% 3$-[(3-Cholamidopropyl) dimethylammonio]-1 propanesulfonate [CHAPS]). The protein concentration was determined using the Bio-Rad protein assay method, and the protein level was adjusted to $5 \mathrm{mg} \mathrm{ml}^{-1}$ in each sample using the 2-D cell-lysis buffer.

\subsubsection{CyDye labelling and two-dimensional fluorescence difference gel electrophoresis (2D-DIGE)}

CyDye DIGE Fluor Cy3 and Cy5 saturation dyes (4 mL, $2 \mathrm{mM}$ ) were used to label the "ods" and "rs" samples, respectively. A third dye, Cy2, was used to label a 50:50 mixture of the two samples, which became the internal standard for the normalisation of spot abundances. The samples were incubated with cyanine dyes for $30 \mathrm{~min}$ on ice under dark conditions before adding a $1 \mu \mathrm{L}$ volume of $10 \mathrm{mM}$ lysine. The reaction was stopped by the addition of $2 \times 2$-D sample buffer ( $8 \mathrm{M}$ urea, $4 \%$ CHAPS, $20 \mathrm{mg} / \mathrm{mL}$ DTT, $2 \%$ pharmalytes and a trace amount of bromophenol blue), and the samples were stored at $-=800^{\circ} \mathrm{C}$ until the 2D-DIGE experiment. Just prior to 2D-DIGE, equal amounts of Cy3and Cy5-labelled samples (30 $\mu \mathrm{g}$ each) were mixed with rehydration buffer. After adding DeStreak ${ }^{\mathrm{TM}}$ rehydration solution (GE Healthcare, Waukesha, WI, USA) containing $0.5 \%$ pharmalyte $\mathrm{pH} 3-10$ in a $250 \mu \mathrm{L}$ final volume, the samples were loaded onto an isoelectric focusing (IEF) strip ( $\mathrm{pH}$ 4-10 linear range; GE Healthcare). The IEF was conducted with standard conditions using Ettan IPGPhore II. After the IEF, the strips were incubated in equilibration buffer (50 mM Tris- $\mathrm{HCl}, \mathrm{pH} 8.8$, containing $6 \mathrm{M}$ urea, 30\% glycerol, $2 \%$ SDS, a trace amount of bromophenol blue and $10 \mathrm{mg} \mathrm{mL}^{-1} \mathrm{DTT}$ ) for $15 \mathrm{~min}$. The strips were then rinsed in equilibration buffer 2 (50 mM Tris- $\mathrm{HCl}, \mathrm{pH} 8.8$, containing $6 \mathrm{M}$ urea, $30 \%$ glycerol, $2 \% \mathrm{SDS}$, a trace amount of bromophenol blue and $45 \mathrm{mg} \mathrm{mL}^{-1}$ iodoacetamide) for $10 \mathrm{~min}$. Then, electrophoresis was performed at $15{ }^{\circ} \mathrm{C}$ on a $12 \%$ SDS-PAGE gel.

Each gel contained three samples pre-labelled with different dyes: (i) the"ods" sample (labelled with Cy3), (ii) the "rs" sample (labelled with Cy5) and (iii) the 50:50 mixture of the two samples used to normalise the spot abundance (labelled with Cy2). For each molecular form (An. gambiae M and An. gambiae S), three different replicate gels were run to compare the effects of the experimental conditions ("ods", "rs") on protein expression, and to allow subsequent statistical assessments ( $N=6$ gels in total). Finally, a seventh gel containing both of the molecular forms from the "ods" conditions and their mixture was run. Comparisons between An. gambiae $\mathrm{M}$ and $\mathrm{S}$ were conducted by overlaying images of the gels and the abundance of each spot was normalised using the results gathered from the seventh gel. The resulting 2D gels were scanned using a Typhoon Trio scanner (Amersham BioSciences) with excitation and emission wavelengths for Cy2-labelled (488/520 nm), Cy3-labelled (548/560 nm) and Cy5labelled $(641 / 660 \mathrm{~nm})$ proteins using settings that resulted in similar relative fluorescence intensities for the Cy3- or Cy5-labelled samples. Image analysis for intensity measurements of the protein spots chosen was performed using the ImageQuantTL and DeCyder software (GE Healthcare), and then, the images were subjected to in-gel analysis and cross-gel analysis using DeCyder software version 6.5 (GE-Healthcare) with a $P$-value $<0.05$ (Student's $t$-test). The ratio of the different protein expression between the species and/or conditions was obtained from ingel DeCyder software analysis (see gel representations inSupplementary data 1).

2.4.3 Protein identification using matrix-assisted laser desorption/ionisation-time of flight (MALDI-TOF) and tandem mass spectrometry (MS)

Protein identification was performed by Applied Biomics, Inc. After analyses of the 2D-DIGE image, selected protein spots of interest (see the data analysis section) were picked up from the gel using an Ettan spot picker (GE Healthcare). The gel spots were washed twice with $25 \mathrm{mM}$ ammonium bicarbonate and 50\% acetonitrile to remove the staining dye. The proteins were digested in-gel at $37^{\circ} \mathrm{C}$ with modified porcine trypsin protease (Trypsin Gold, Promega) (Rosenfeld et al., 1992). The digested tryptic peptides were desalted using Zip-tip C18 (Millipore, Billerica, MA), mixed with $0.5 \mu \mathrm{L}$ of $\alpha$-cyano-4hydroxycinnamic acid (CHCA) matrix and spotted into wells of a MALDI plate. Mass spectra of the peptides in each digested spot were obtained using MALDI-TOF (MS) and TOF/TOF (tandem MS/MS) equipment (AB Sciex). The MALDI-TOF mass spectra were acquired in reflectron positive ion mode, averaging 2000 laser shots per spectrum. TOF/TOF tandem MS fragmentation spectra were acquired for each sample, averaging 2000 laser shots per fragmentation spectrum on each of the 5-10 most abundant ions present in each sample (excluding trypsin autolytic peptides and other known background ions). Both the resulting peptide mass and the associated fragmentation spectra were submitted for database search using GPS Explorer software version 3.5 (Applied Biosystems) equipped with the MASCOT search engine (http://www.matrixscience.com, Matrix science) to identify proteins from the National Center for Biotechnology Information non-redundant protein sequence database (NCBInr), restricted to An. gambiae. The searches were performed without constraining the protein molecular weight or isoelectric point, with carbamidomethylation and oxidation as variable modifications, and with one missed cleavage allowed in the search parameters. The highest protein scoring hit with a protein score confidence interval over $95 \%$ from the database search for each $2 \mathrm{D}$ gel spot was accepted as positive identification.

\subsection{Data analysis}

All statistical procedures were conducted with the $R$ 2.15.0 statistical software (R Development Core Team, 2008). Before analysis, the normal data distribution and homoscedasticity of each dataset were determined using Shapiro-Wilk and Bartlett's tests, respectively. Accordingly, parametric or non-parametric tests were further processed. Analyses of covariance (ANCOVA) were performed to address the effects of the molecular form, experimental conditions, and female age on the body water content of female mosquitoes during development (i.e., pupae to 24-h-old) and under exposure to $5-7 \% \quad \mathrm{RH}$ of "rs" and "ods" acclimated mosquitoes. Dry mass was used as a covariable in these models. The effect of molecular form, experimental conditions, and female's age on female's dry mass was assessed using a three-way ANOVA. Model simplification used stepwise removal of terms followed by the estimate of Akaike information Criterion (AIC), as described by (Crawley, 2007). Term removals that significantly reduced explanatory power were retained in the minimal adequate model. Tukey's post hoc procedures were used to perform comparisons among the levels of significant factors.

Further, non-parametric regression analyses (Cox proportional hazard models) were performed to examine the effect of molecular forms (M, S), and experimental conditions ("rs, "ods") on the survival of the 24-h-old females submitted to both desiccating (5-7\% RH) and control conditions (80\% RH). For these analyses, the time to death was defined as the response variable, and the mosquito molecular form, dry mass, experimental condition ("rs" vs. "ods"), and exposure to desiccating conditions in the plastic vial $(5-7 \%$ vs. $80 \%)$ were considered as the explanatory variables. Model simplification used stepwise removal of terms, where the significance of the terms was estimated using the difference in Akaike's information criterion (AIC). As all mosquitoes were dead at the end of this experiment, no survival time was censored. Survival distributions were illustrated by Kaplan-Meier survivorship curves.

Multivariate discriminant analyses were used to assess differences in the amount of amino acids among molecular forms, experimental conditions, and females'age (i.e., 1 -h and 24-h-old mosquitoes). The amino acid concentrations were log-transformed $\left(x=\log _{10}[X+1]\right)$ to fulfil the assumption of normally distributed 
residuals. We first performed MANOVAs to address differences in amino acid amounts between the two molecular forms of An. gambiae, the two experimental conditions, and across the females' age classes. Samples for which some of the amino acids were not reliably quantified (Signal/Noise $<10$, or concentration $<$ Quantification Limit) were discarded from the analysis. Class separation was further investigated using linear discriminant analyses (LDA). Taking into account the significant effect of the molecular form on the amino acid signatures, LDA were performed separately for An. gambiae S and M. The significance distribution of each LDA was assessed using Monte Carlo 10,000 permutations $(P<0.001)$. Two-way ANOVAs (where the experimental conditions and females' age were considered as continuous variables) were conducted in parallel for each individual metabolite and for each molecular form. These analyses were followed, when necessary, by Tukey post hoc tests among levels of significant factors. The betweenand within-groups degrees of freedom together with the $F$-value are reported. The $P$-values were adjusted using the BenjaminiHochberg algorithm (Benjamini and Hochberg, 1995) to control the false discovery rate induced by multiple comparisons $(P<0.05)$. Metabolites for which no significant difference was observed for at least one variable were discarded from the discriminant analysis to accurately explain the physiological differences among the groups. For the sugar amounts, nonparametric Kruskal-Wallis tests were conducted to examine possible differences among the two molecular forms of An. gambiae, the two experimental conditions, and the two female age classes (1-h- and 24-hold). These tests were followed by a Bonferroni correction resulting in a decrease threshold of significance to $P<0.01$.

Finally, for average-fold differences in protein abundance, protein quantities from each 2D-DIGE gel were normalised (Log abundance). The averaged-fold differences in spot abundance were then calculated for the following ratios: (i) An. gambiae M "rs"-/-An. gambiae M "ods"; (ii) An. gambiae S"rs"-/-An gambiae S "ods"; (iii) An. gambiae M "rs"-/-An gambiae S "rs"; and (iv)An. gambiae M “ods"-/-An gambiae S "ods". For each ratio, differences in protein expression were assessed using Student's $t$-tests on individual proteins $(P<0.05)$

\section{Results}

\subsection{Changes in body water content and dry mass}

The fresh and dry masses of 909 mosquitoes were measured to determine their body water content. Overall, the water content of both $\mathrm{M}$ and S forms reared under "rs" or "ods" conditions decreased from pupae to 24-h-old mosquitoes (ANCOVA, $d d l=2, F=171.33, P<0.001$; Fig. 2A), and from $\mathrm{o}$ to 12 -h exposure to low (5-7\%) $\mathrm{RH}$ (ANCOVA, $d d l=4, F=138.22, P<0.001$; Fig. 2B). Significant variations of body water contents were observed between molecular forms and experimental conditions from pupae to 24-h-old mosquitoes (ANCOVA, $d d l=1, F=9.80, P<0.01 ; F=24.79, P<0.001$, respectively). Although the $M$ form exhibited higher amounts of body water when the females were reared under"ods" conditions, no such a difference was observed in the $\mathrm{S}$ form from pupae to 24-h-old females (Fig. 2A). In addition, acclimation to "rs" or "ods" conditions had a significant effect on the body water content of females exposed to low $\mathrm{RH}(5-7 \%)$ (ANCOVA, $d d l=1, F=195.03, P<0.001$ ), and this effect is distinct according the molecular form (ANCOVA, $d d l=3, F=4.51, P<0.01$ ). Accordingly, "ods"specimens had significantly higher water content than "rs" ones in M molecular forms, but no such a significant difference was observed in the $\mathrm{S}$ forms (Fig. 2B). Dry mass of both $\mathrm{M}$ and $\mathrm{S}$ females significantly affect the body water contents of female's mosquitoes from pupae to 24-h-old mosquitoes (ANCOVA, $d d l=1, F=239.90, P<0.001$ ), and from $\mathrm{O}$ to $12 \mathrm{~h}$ exposure to $5-7 \% \quad \mathrm{RH}$ (ANCOVAddl $=1, F=416.44, P<0.001$ ). An increase in dry mass correlated with a decrease in body water content (Figs. 2 and 3). No change in dry mass was observed from 3 - $\mathrm{h}$ to 12 -h exposure to $5-7 \% \mathrm{RH}$ conditions in both $\mathrm{M}$ and $\mathrm{S}$ forms (Fig. $\mathrm{3}^{\mathrm{B}}$ ).
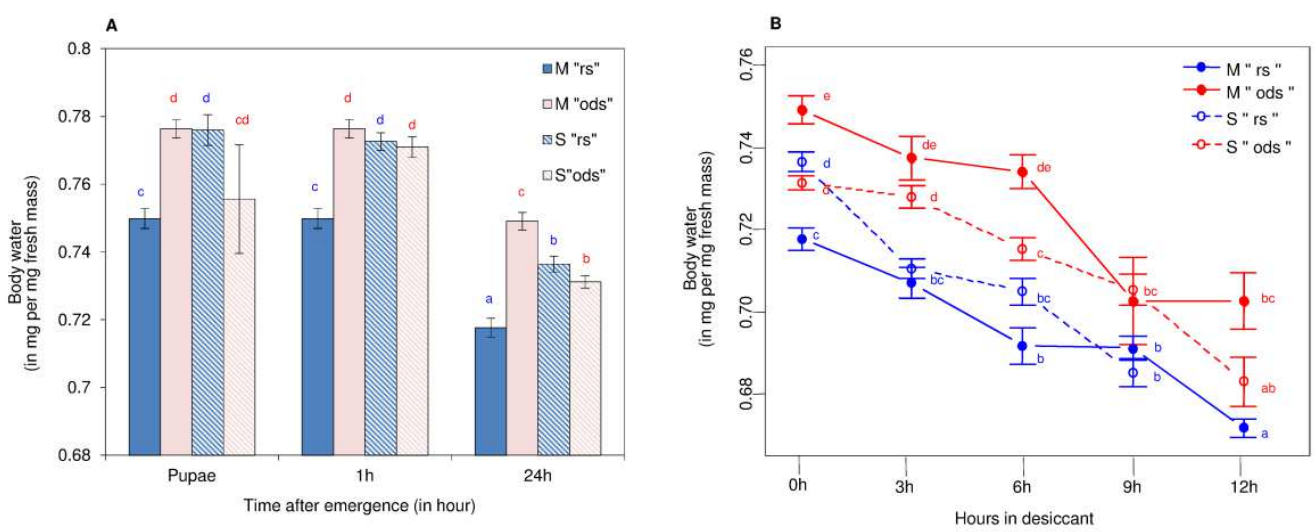

Fig. 2 Mean ( \pm s.e.) body water content (in mg water per mg fresh mass) in An. gambiae M (solid bars and lines) and S (dashed bars and lines) forms reared under "rs" (blue bars and lines), and "ods" conditions (red bars and lines). Panel A shows body water content variation from pupae to 24-h-old females exposed to "rs" or "ods" conditions. Panel B reflects body water content variations from 24-h-old to 36-h-old females acclimated to "rs" or "ods" conditions and exposed to low RH (5-7\%). Letters above the bars report significant differences $(P<0.05)$. (For interpretation of the references to colour in this figure legend, the reader is referred to the web version of this article.)
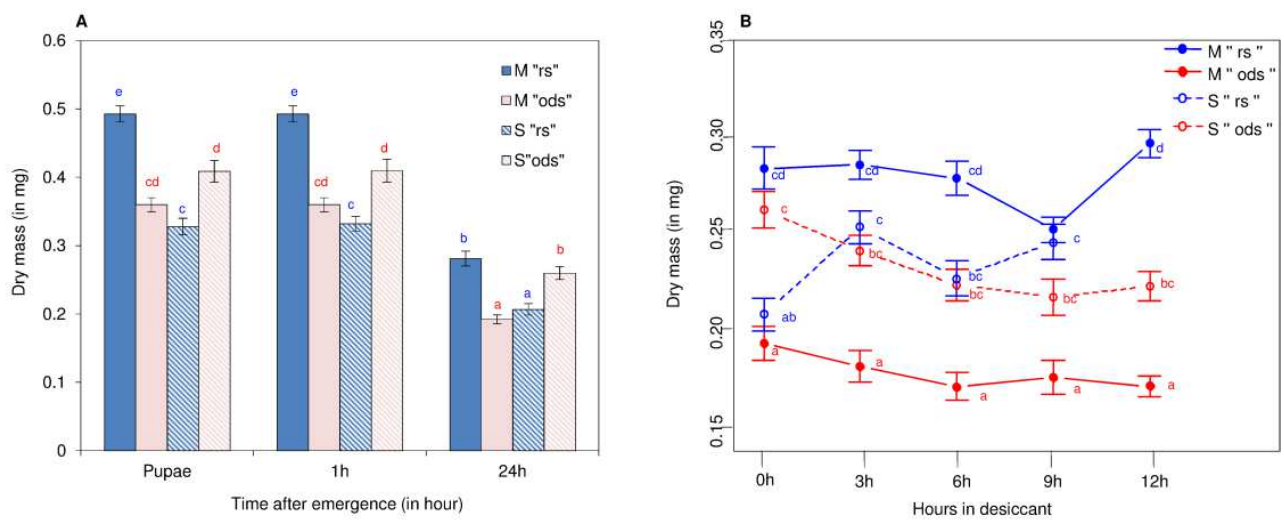
Fig. 3 Mean ( \pm s.e.) female’s dry mass (in mg) in An. gambiae M (solid bars and lines) and S (dashed bars and lines) forms reared under "rs" (blue bars and lines), and "ods" conditions (red bars and lines). Panel A shows dry mass variation from pupae to 24-h-old females exposed to "rs" or "ods" conditions. Panel B reflects dry mass variations from 24-h-old to 36-h-old females acclimated to "rs" or "ods"conditions and exposed to low RH (5-7\%). Letters above the bars report significant differences $(P<0.05)$. (For interpretation of the references to colour in this figure legend, the reader is referred to the web version of this article.)

3.1.1 Survival

Overall, control females exposed to high RH (80\%) survived longer than those exposed to low RH $(5-7 \%)$ conditions (LRT $\chi^{2}{ }_{1}=$ 182.54, $P<0.001$; Fig. ${ }^{4}$ A-B) and body mass positively affected survival duration (LRT $\left.\mathrm{X}^{2}{ }_{1}=121.36, P<0.0001\right)$. In both control (Figure $4 \mathrm{~A}$ ) and low RH conditions (Fig. 4B), the experimental conditions ("rs", "ods")

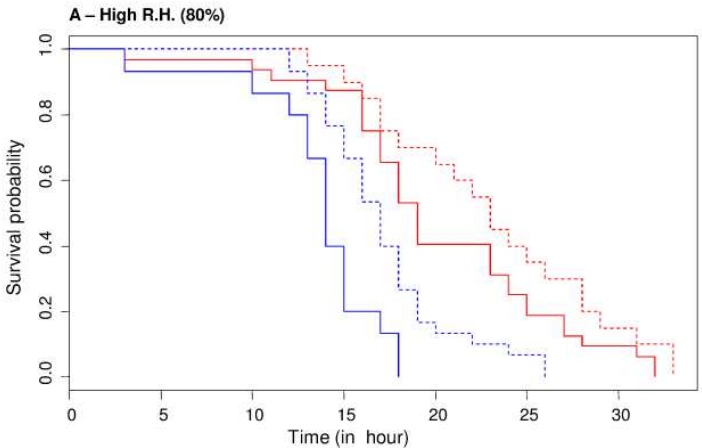

significantly influenced mosquitoes' survival (LRT $X^{2}{ }_{1}=60.41, P<$ o.001): females survived longer when they had been reared under "ods" as compared to "rs" conditions. This was particularly true for mosquitoes exposed to low RH conditions (LRT $\mathrm{X}^{2}{ }_{1}=10.10, P<0.001$; ${ }^{2}$ ig. ${ }^{4} \mathrm{~B}$ ).

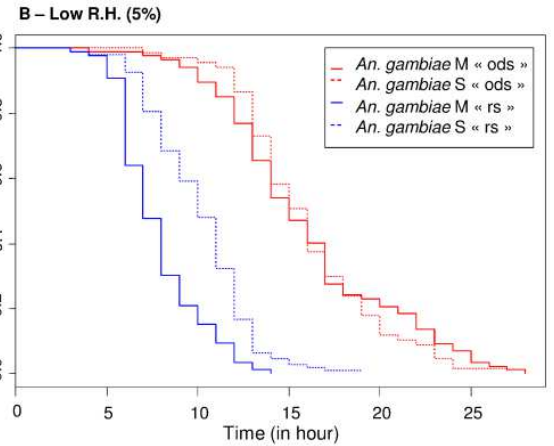

Fig. 4 Kaplan-Meier survival probability curves for 24-h-old female An. gambiaeM (solid lines) and S (dotted lines) reared under "rs" (blue) and "ods" (red) conditions. Panel A: control high RH conditions (80\%); panel B: exposure to low RH (5-7\%). (For interpretation of the references to colour in this figure legend, the reader is referred to the web version of this article.)

\subsection{Metabolic fingerprinting}

\subsubsection{Circulating amino acid content}

Of the 22 amino acids listed in our external standard, 21 were detected and quantified. In particular, we were unable to provide reliable measurements of cysteine amounts in our samples, and this amino acid was therefore discarded from further analysis. Similarly, for technical reasons, some amino acids were not reliably quantified in some samples (signal/noise $<10$, or concentration $<$ quantification limit). Thus, four samples were discarded from the analysis to successfully achieve the LDA, including three samples of 1-h-old specimens of the M form (two reared under "rs", and one under "ods"), and one sample of 24-h-old female of An. gambiae S reared under "rs" conditions.

Significant differences in the concentration of at least one amino acid were found between the two molecular forms of An. gambiae, between 1-h and 24-h-old females, and between the two experimental conditions ("rs", "ods"; Table 1). The amino acid content of the two molecular forms differed according to the seasonal conditions and females' age, as demonstrated by the significance of the interaction terms (Table 1).

Table 1 Results of the MANOVA computed on the amino acid contents of individual females exposed to the different experimental conditions.Numeric data are rounded to two decimal digits. The Pillai trace was multiplied by $10 . \cdots P<0.0001 ; \cdots P<0.05$; “ns": $P>0.05$.

\begin{tabular}{|c|c|c|c|c|c|c|}
\hline Dataset & Effects & $d d l$ & Test stat & F-value & Num Df & $P$-value \\
\hline \multirow{7}{*}{ ( $N=54$ samples $)$} & Experimental condition & 1 & 87.65 & 5.74 & 21 & $* * *$ \\
\hline & Molecular form & 1 & 82.36 & 3.78 & 21 & ** \\
\hline & Females' age & 1 & 91.91 & 9.20 & 21 & $* * *$ \\
\hline & Molecular form : Experimental condition & 1 & 82.31 & 3.76 & 21 & ** \\
\hline & Females' age : Experimental condition & 1 & 90.80 & 7.98 & 21 & $* * *$ \\
\hline & Molecular form : Females' age & 1 & 81.83 & 3.64 & 21 & ** \\
\hline & Molecular form : Female' age : Experimental condition & 1 & 68.59 & 1.76 & 21 & ns \\
\hline
\end{tabular}

3.2.2 Effects of the environmental conditions and females'age on the circulating amino acid composition of An. gambiae $M$

The amino acid composition of female An. gambiae M differed significantly between the two experimental conditions (MANOVA, $F_{1,10}=5.30, P<0.01$ ), and between 1-h and 24-h-old females (MANOVA, $\quad F_{1,10}=15.76, P<0.001$ ). Amino acid profiles were differentially altered in 1 -h and 24-h-old females exposed to "rs" and "ods" conditions, as demonstrated by the significance of the interaction term (MANOVA, $F_{1,10}=4.18, P<0.01$ ).

Ten out of 21 amino acids showed significant differences among experimental conditions, and were further considered for the LDA (Supplementary data 1 ). The 11 remaining amino acids (i.e., alanine, aspartate, GABA, glycine, isoleucine, leucine, methionine, ornithine, proline, threonine, and tryptophan) were discarded from subsequent analysis. The first axis (LD1) accounted for $40.8 \%$ of the total inertia, and the variation among groups was 9.98 times higher than the variation within groups (Fig. 5A). LD1 was mainly supported by the variations of the 10 significant amino acids (mainly arginine, glutamine, histidine, phenylalanine, tyrosine, and valine) which showed higher amounts in 1h-old females, and more particularly in females reared under "ods"conditions (Supplementary data 2 and 3). The second axis (LD2) accounted for $34.9 \%$ of the total inertia and the variation among groups was 5.41 times higher than the variation within groups. This axis represented a clear cut-off between females reared under "rs" and "ods" experimental conditions. This axis was mainly supported by the variation in histidine content, whose amounts were higher in 1-h-old females reared under "ods" conditions (Supplementary data 2 and 3 ). 


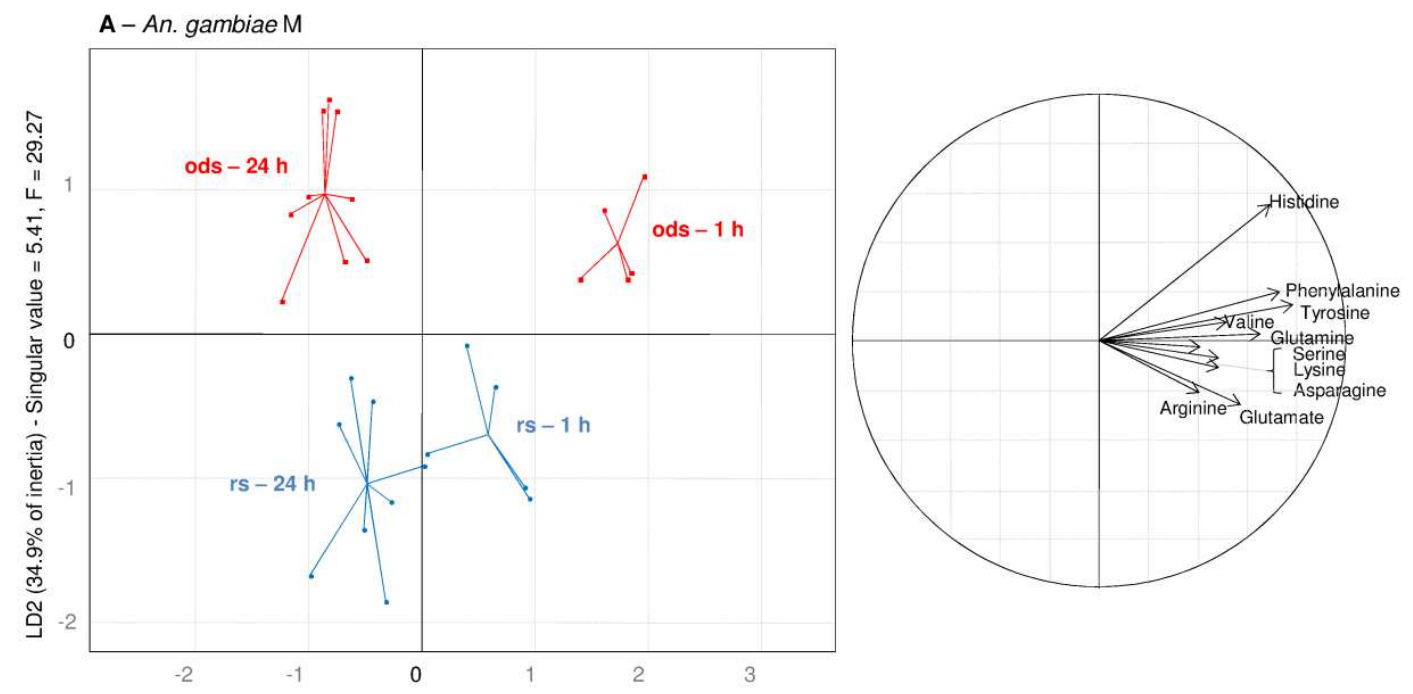

LD1 $(40.8 \%$ of inertia) - Singular value $=9.98, F=99.67$

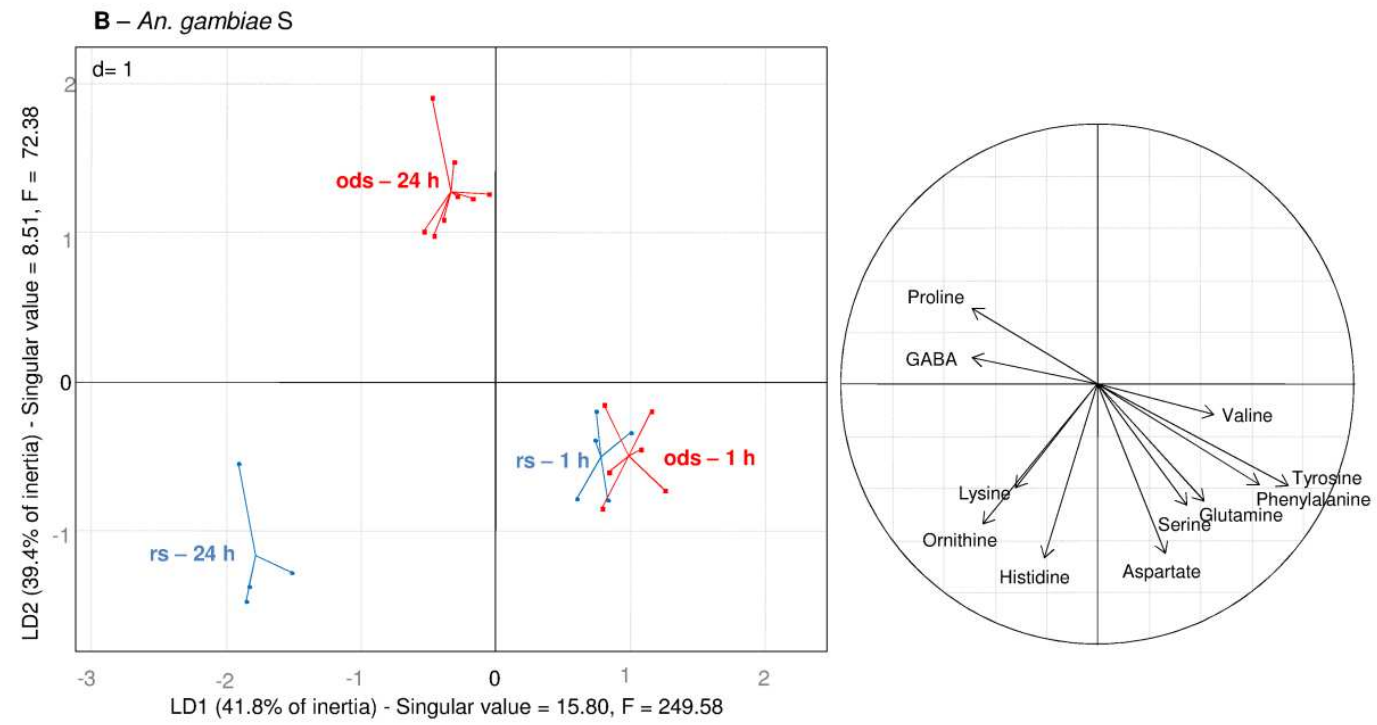

Fig. 5 Left: Sample projections onto the first LDA discriminant plane for femaleAnopheles gambiae M (28 samples, A) and S (23 samples, B) reared under "ods"(red squares) and "rs" (blue dots) conditions. Singular values refer to the ratio of the between-class and within-class inertia. Right: correlation circles depict thenormalised relation (from -1 to 1) between each amino acid and LDA axes. (For interpretation of the references to colour in this figure legend, the reader is referred to the web version of this article.)

\subsubsection{Effects of environmental conditions and females' age on} the circulating amino acid composition of An. gambiaes

The amino acid composition of An. gambiae $\mathrm{S}$ females differed significantly between experimental conditions (MANOVA, $F_{1,11}=7.17, P<0.01$ ), and between 1-h and 24-h-old females (MANOVA, $F_{1,11}=28.19, P<0.001$ ). Amino acid profiles were differentially altered in 1 -h and 24-h-old females exposed to "rs"and "ods" conditions, as demonstrated by the significance of the interaction term (MANOVA, $F_{1,11}=6.85, P<0.01$ ).

A LDA was performed to further analyse the differences found among the experimental groups (Fig. 5B). Of the 21 amino acids considered in this study, 11 showed significant differences among groups, and were therefore considered for the LDA (Supplementary data 4). To gain insights into the separation among groups, the 10 amino acids showing a constant concentration regardless of the experimental conditions (i.e., alanine, arginine, asparagine, glutamate, glycine, isoleucine, leucine, methionine, threonine, and tryptophan) were discarded from subsequent analysis.

The first axis (LD1) accounted for $41.8 \%$ of the total inertia, and the variation among groups was 15.8 times higher than the variation within groups. LD1 corresponded to a clear cut-off between 1-h and 24h-old females, and was mainly supported by variations in the contents of GABA, ornithine, phenylalanine, proline, tyrosine, and valine. Amino acid composition of 1-h-old females from "rs"and "ods" conditions overlapped and these groups were notably characterised by accumulation of phenylalanine, tyrosine, and valine (Supplementary data 3 and 4 ).

The second axis (LD2) accounted for $39.4 \%$ of the total inertia and the variation among groups was 8.5 times higher than the variation within groups. This axis was mainly supported by variations in the contents of several amino acids, of which aspartate, histidine, and ornithine can be mentioned (Supplementary data 3). LD2 corresponded to a contrast between 24-h-old females exposed to "ods" conditions and those exposed to "rs" conditions, with low levels of aspartate, histidine, and ornithine in the 24-h-old females exposed to "ods" conditions.

\subsection{Sugar content}

Of the six sugars contained in our reference standard, only two (i.e., galactose and glucose) were reliably quantified in the mosquito samples; the other four (i.e., arabinose, fructose, ribose, and trehalose) 
were below the quantification limit of our equipment. Both the galactose and glucose amounts were significantly higher in the 24-h-old M and S females exposed to the "ods" conditions (Kruskal-Wallis test, $P<0.01$ )
(Fig. 6A-D). The glucose and galactose amounts did not differ in the 1-hold females, except for females of the $\mathrm{M}$ form, whose glucose amounts decreased under the "ods" conditions (Fig. 6C).

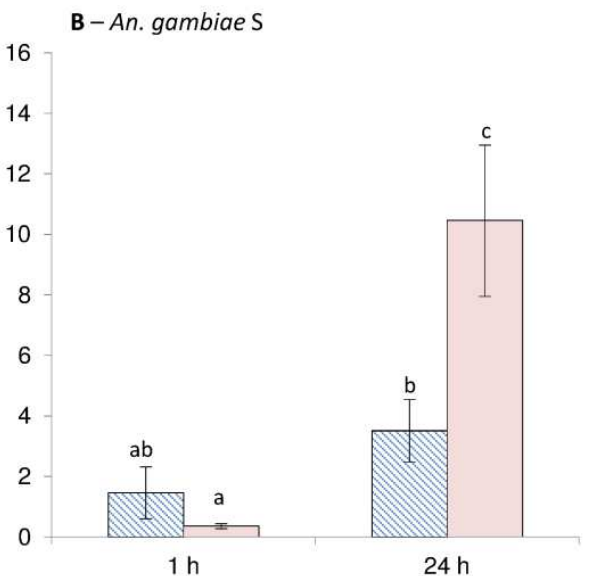

D-An. gambiae S

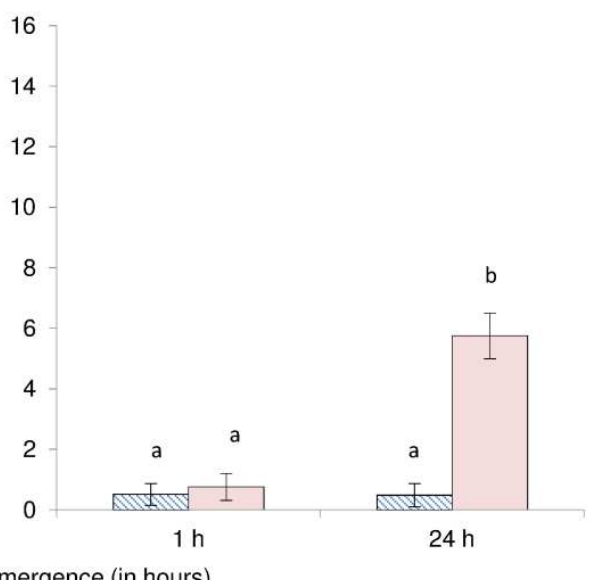

Fig. 6 Mean ( \pm s.e.) galactose (A and B) and glucose (C and D) levels (in nmoles mg-1 dry mass) in 1-h and 24-h-old females of An. gambiae M (A and C) and S (B and D). Dashed blue bars correspond to the females reared under "rs" conditions and solid red bars correspond to females reared under "ods" conditions. Letters above the bars report significant differences after Bonferroni correction to account for multiple tests $(P<0.01)$. (For interpretation of the references to colour in this figure legend, the reader is referred to the web version of this article,

\subsection{Proteomic assays}

\subsubsection{Protein content in emerging females}

A total of 109 spots, corresponding to proteins with molecular masses ranging from 14 to $150 \mathrm{kDa}$, and isoelectric points between 4 and 9, exhibited significant variations in at least one molecular form and/or experimental condition. Based on an average difference of at least 1.3fold (absolute value), 41 spots were selected, which corresponded to 33 distinct proteins.

\subsubsection{An. gambiae Mform}

Fifteen proteins exhibited significant variation between the "rs" and "ods" conditions in the 1-h-old females of An. gambiae M, of which 10 were more abundant when the females were grown under the "ods" conditions (Table 2,Supplementary data 5 and 6). This group included four proteins engaged in striated muscle contraction (spots \#1,
\#37-39, \#45, \#57-60), a proteolysis enzyme (spots \#24-25), a hexamerin (spot \#2), an arylphorin (spot \#3), a catalase (spot \#19), an enzyme involved in DNA translation (spot \#55), and a $\mathrm{NADH}$ dehydrogenase (spot \#56; Table 2, Supplementary data 7). A RR-2 cuticular protein 70 (spot \#67) was also significantly more abundant under the "ods"conditions (Student $t$-test, $P<0.001$ ) although its fold change was only 1.28 . Five proteins were found in lower amounts when the females were exposed to the "ods" conditions (Table 2, Supplementary data 5 and 6), including three storage proteins (spots \#9, 12 and 21), an oxygen transporter (spot \#64), and an ATP synthase beta subunit (spot \#67). 
Table 2 Protein spots displaying differential abundance (average fold difference $>1.3$, absolute value; $P<0.05$ ) between the "rs" and "ods" experimental conditions in 1-h-old female An. gambiae M (orange) and $\mathrm{S}$ (green). Black numbers represent protein ratios that did not significantly vary between the two experimental conditions.

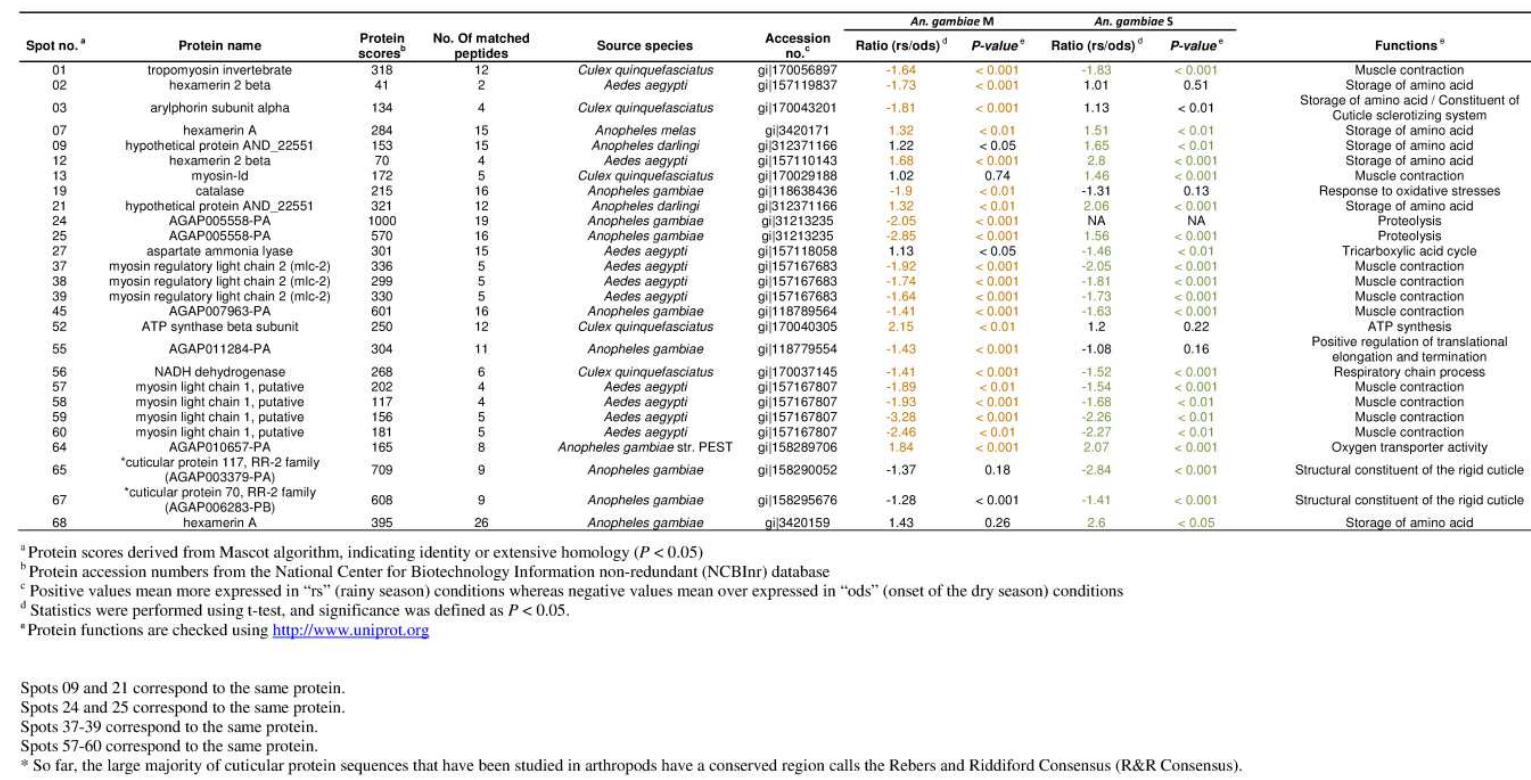

\subsubsection{An. gambiae S form}

Fourteen proteins exhibited significant variations between the "rs" and "ods" conditions in the 1-h-old females of An. gambiae S, of which 8 proteins were more abundant in the females exposed to the "ods" conditions (Table 2,Supplementary data 5 and 6). This group included two constituents of the rigid cuticle (RR-2 cuticular protein 70 and 117 , spots $\# 67$ and $\# 65$, respectively), four proteins involved in striated muscle contraction (spots \#1, \#37-39, \#45, \#57-60), two enzymes involved in metabolic pathways (i.e., aspartate ammonia lyase and NADH dehydrogenase: spots \#27, 56; Table 2, Supplementary data 5). The amounts of six other proteins were reduced when the 1-h-old females were exposed to the "ods" conditions (Table 2, Supplementary data 5 and 6). These proteins included three storage proteins (spots \#7, 9, 12, 21, 68), an oxygen transporter (spot \#64), a protein involved in motor activity (spot \#13), and an enzyme involved in proteolysis processes (spot \#25).

3.4.4 Difference in protein composition between the two molecular forms
Nine proteins exhibited the same pattern in the two molecular forms: five proteins were more abundant in females grown under the "ods" conditions, whereas the levels of four others decreased under these conditions (Table 3). A total of 24 proteins showed significant variations between the females of An. gambiae $\mathrm{M}$ and $\mathrm{S}$ exposed to the "rs" or "ods" conditions (Table 3, Supplementary data 6). Six proteins were more abundant in females of An. gambiae S, whatever the experimental conditions ("rs" or "ods"), among which prophenoloxidase (spot \#76), citrate synthase (spot \#84), isocitrate dehydrogenase (spot \#85), and glutathione transferase (spot \#99) can be mentioned (Table 3, Supplementary data 7). The RR-2 cuticular protein 123 (spot \#101) was also significantly more abundant under the "ods" conditions (Student $t$-test, $P<0.001$ ), although its fold change was only 1.27 . In addition, a phosphorylase (spot \#75) was more abundant in An. gambiae S compared to An. gambiae $\mathrm{M}$ when the females were exposed to the "ods" conditions, but no differential expression was found in the "rs"conditions. Arginine kinase (spot \#96) was always more abundant in An. gambiaeM, whatever the experimental conditions. 
Table 3 Protein spots displaying differential abundance (average fold difference $>1.3$, absolute value; $P<0.05$ ) between 1-h-old female An. gambiae M and S reared under the "ods" (red) and "rs" (blue) conditions, respectively. Black numbers represent protein ratios that did not significantly vary between the two experimental conditions. In grey, protein spots already shown in Table 2.

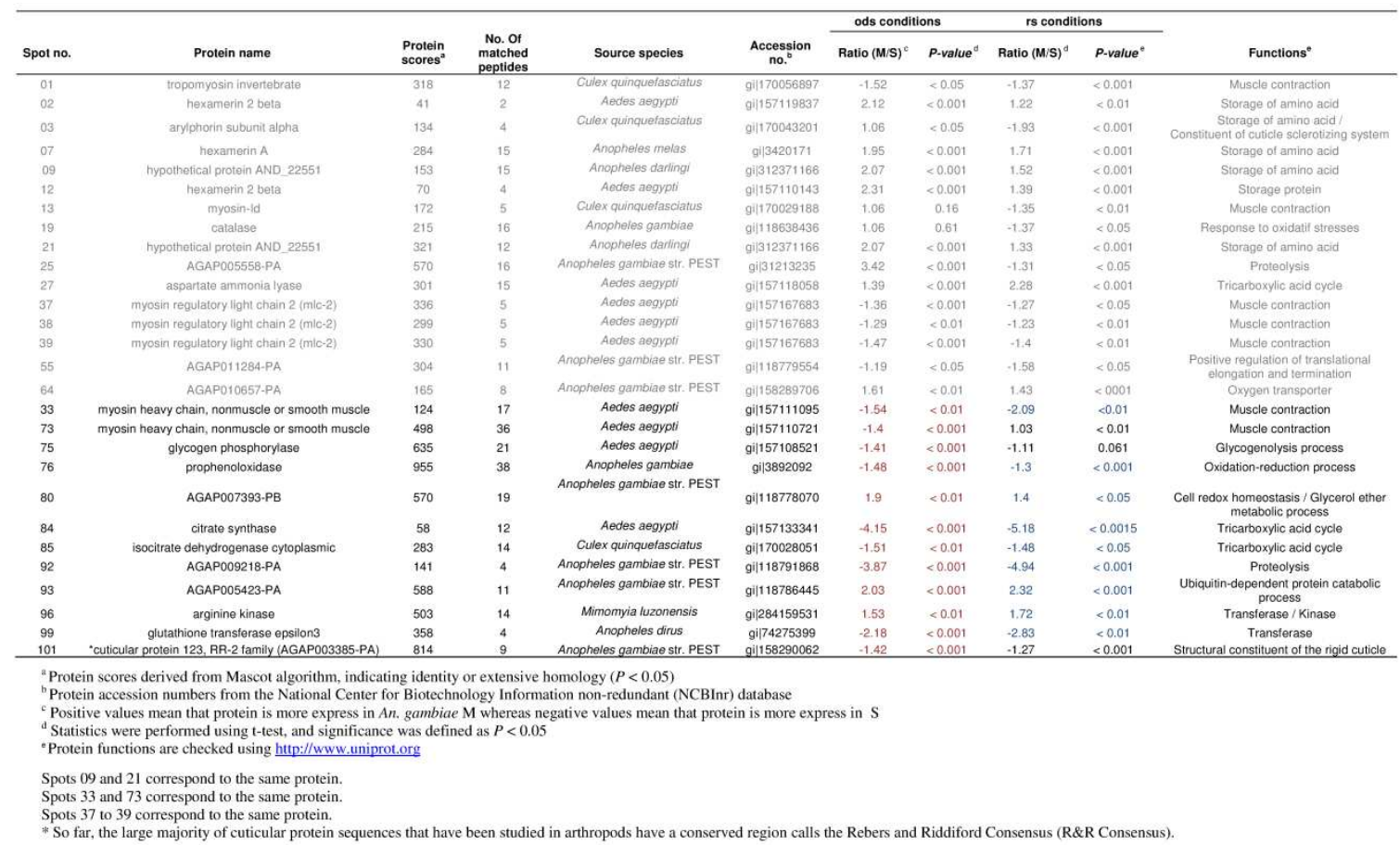

\section{Discussion}

In the present work, we provide novel insights into the physiological and biochemical changes in freshly emerged (1-h and 24-hold) mosquitoes An. gambiae s.s. that accompany acclimation to contrasting environmental conditions they experienced during the onset of the dry season in the Burkina-Faso. Our data demonstrates that developmental acclimation to dry season conditions enhances the desiccation tolerance and resistance (i.e., increases survival and reduces body water loss) of mosquitoes exposed to low $5-7 \% \mathrm{RH}$ conditions in both $\mathrm{M}$ and $\mathrm{S}$ forms. We observed significant metabolic and biochemical rearrangements elicited by exposure of immature stages to dry conditions in both molecular forms. These changes include increased amounts of circulating sugars when the mosquitoes were reared under "ods" conditions, changes in both circulating amino acid fingerprints and protein expression supporting adjustments in the cuticle composition of females of An. gambiae M (e.g.,increased amounts of tryptophane, tyrosine, valine, and RR2 cuticular proteins), and higher expression of enzymes involved in intermediary metabolism in An. gambiae S (e.g., increased amounts of aspartate ammonia lyase citrate synthase, isocitrate dehydrogenase, and proline), suggesting higher metabolic activity in this latter species.

\subsection{Increased sugar amounts may be indicative of water stress in An. gambiae females}

The survival data of An. gambiae $\mathrm{M}$ and $\mathrm{S}$ females reared under the "rs"and "ods" conditions and further exposed to desiccating conditions suggests the existence of distinct seasonal physiological and biochemical adjustments at the emergence of the adults. The efficient management of body water content represents one of the most prominent challenges for mosquitoes during the dry season. Our results show that the dynamics of body water loss differed between females reared under "rs" and "ods" conditions in An. gambiae M, but no such a significant difference was observed in $\mathrm{S}$ form. This suggests that the $\mathrm{S}$ form lacks distinct phenotypes from one season to another which would enhance their desiccation resistance. Even if the accumulation of organic osmolytes like amino acids may contribute preventing body water loss (Zachariassen, 1996), we found no evidence supporting such accumulation in the 24-h-old females of either of the molecular forms reared to the "ods" conditions. Compatible solutes other than amino acids, including sugars (trehalose and sucrose), and polyols (glycerol, myo-inositol, and sorbitol) can also prevent body water loss (Elnitsky et al., 2008; Thorat et al., 2012; Yancey, 2005). Although, trehalose was found in small amounts regardless of molecular form or experimental condition, the concentration of circulating glucose and galactose increased in females exposed to the "ods" conditions. Increased amounts of glucose were already observed during cryoprotective dehydration in the Antarctic midge Belgica antarctica (Diptera, Chironomidae) (Elnitsky et al., 2008). It is, however, possible that the increased energetic demands in the 24-h-old food deprived females partly explained this increase in circulating glucose, although this would be observed in all experimental conditions. Thus, the different energy and water contents offered by carbohydrates and stored lipids may guide the determination of the most appropriate substrates that must be catabolised during periods of food deprivation and desiccation. Indeed, lipids produce more energy compared to carbohydrates (Withers, 1992), but glycogen degradation releases higher amounts of metabolic water, as it binds up to 5 times its mass in water molecules (Gibbs et al., 1997; Schmidt-Nielsen, 1990). We thus suggest that the increased glucose and galactose amounts we observed in females exposed to desiccating conditions represent the endured water stress, which is consistent with earlier data collected fromDrosophila melanogaster (Marron et al., 2003). Finally, it is also possible that mosquitoes use these two sixcarbon sugars for the biosynthesis of chitin precursors, and glycan residues during cuticle differentiation (Im et al., 2010; Muir and Lee, 1969).

4.2 Evidence of post-emergence adjustments of the cuticle composition in response to seasonal changes in An. gambiae $M$

In addition to the accumulation of organic and inorganic solutes in insects'hemolymph, adjustments of the cuticle composition may help mosquitoes to limit body water loss. Cuticle differentiation, starting during late embryogenesis, continues, and is soon completed after the establishment of the imaginal cuticle (Truman and Riddiford, 2000). Chemically, insects' cuticle contains proteins, peptides, and amino acids. Among these compounds, phenylalanine, tryptophan, tyrosine, and 
valine are particularly important for cuticle sclerotisation (Neville, 1975; Stankiewicz et al., 1996; Williams et al., 1987), and can be selectively favoured in the insect diet to maximise growth and cuticle synthesis (Behmer and Joern, 1993). Three (phenylalanine, tyrosine, valine) out of these four amino acids were characterised by decreased levels from 1-hold to 24-h-old females of both $\mathrm{M}$ and $\mathrm{S}$ forms suggesting that they were at least partially used for the well-known process of cuticle settlement (Behmer and Joern, 1993; Neville, 1975; Stankiewicz et al., 1996; Truman and Riddiford, 2000; Williams et al., 1987).

Of particular interest, the 1-h-old females of An. gambiae M reared under the "ods" conditions exhibited 2- to 6-fold higher quantities of phenylalanine, tyrosine, and valine compared to counterparts reared under the "rs" conditions. Interestingly, supporting our results on body water contents, no such a difference in these aromatic amino acids was reported in An. gambiae S. Phenylalanine, tyrosine, and valine are known to improve the hydrophobicity of the insect cuticle (Goltsev et al., 2009). Moreover, tyrosine and its derivatives assist exoskeleton hardiness by interacting with proteins (Behmer and Joern, 1993; Brunet, 1963), and also represent primary components to form sclerotin, and melanin in the newly formed insect cuticle (True, 2003). Similarly, high histidine contents were also found in 1-h-old An. gambiae M females reared under the "ods" conditions, and residues of this amino acid are present in high amounts in hard (rigid) cuticle proteins (Iconomidou et al., 2005).

The cuticle wax layer is cited as one of the most crucial arthropod adaptations to prevent water loss and there is evidence in the literature supporting a positive relationship among cuticle thickness, rigidity, and body water loss (Benoit et al., 2010). Higher amounts of RR-2 cuticular proteins in insects exposed to dry conditions might increase desiccation resistance by augmenting the hardness of the cuticle (Brunet, 1963; Li and Denlinger, 2009), whereas RR-1 proteins are involved in flexible ones (Willis et al., 2005). In the present study, cuticular proteins 70 and 117 , which belong to the RR-2 family, were 1.28 - to 2.84 -fold more abundant in mosquito females reared under "ods"conditions, and this may assist the level of desiccation resistance of the mosquitoes during the dry season. Arylphorins were also 1.81-fold more abundant in newly emerged An. gambiae M females reared under "ods" conditions. These proteins are assumed to play a significant role in the cuticle sclerotisation process, but it remains unknown if they directly act as components of cuticle structure, or if they are degraded in the cuticle for the further use of their amino acid components (König et al., 1986; Telfer and Kunkel, 1991). Of note, arylphorins contain a large amount of aromatic amino acids, which supports our earlier hypothesis on the use, and thus decreased amounts of these amino acids from 1-h to 24-h-old anopheline females.

Finally, changes in cytoskeleton elements (tropomyosin, myosin light and regulatory chains) were also observed in newly emerged females of both $\mathrm{M}$ and $\mathrm{S}$ forms. Myosin light chain 1 (MLC-1), and myosin regulatory light chain 2 (MLC-2) were up-regulated in the $\mathrm{M}$ and $\mathrm{S}$ females reared under the "ods" conditions. While myosin heavy chains are well known to do the actual work in muscle contraction (Goldspink et al., 1992), the role of light alkali chains remains unclear. Furthermore, our protocol did not permit us to assess whether tropomyosin belonged to the muscle or non-muscle isoform (Bullard and Pastore, 2011; Holmes, 2011). Overall, these cytoskeleton elements appear to be altered in insects exposed to a range of experimental stress conditions (Colinet et al., 2012, 2013), but the functional roles of this modulation most often remain hypothetical. Further investigations will have to be conducted to examine the exact nature of cuticle remodelling at the onset of the dry season in these mosquitoes.

\subsection{Proteomics suggests a higher activity of aerobic metabolism in An. gambiae $\mathbf{S}$}

Signs of energetic metabolism adjustments were found in both molecular forms in the "ods" conditions. However, high variations in the amount of enzymes of the intermediary metabolism were observed in An. gambiae S. In this mosquito, the 1-h-old females were always characterised by higher amounts of enzymes involved in glycogenolytic and proteolytic processes, regardless of the experimental conditions. In particular, we found 1.41-fold more glycogen phosphorylase in the S form than in the M form under "ods" conditions. Moreover, isocitrate dehydrogenase and citrate synthase, which represent two key enzymes that strongly control the TCA cycle activity (Kültz, 2005), increased 1.6to 4.0-fold, respectively, in the $\mathrm{S}$ form compared to the $\mathrm{M}$ form when reared in "ods"conditions. Interestingly, the two enzymes are overexpressed in colonies of the 2La karyotype of An. gambiae M (Cassone et al., 2011) which are characterised by increased desiccation tolerance (Gray et al., 2009; Rocca et al., 2009).

Aspartate ammonia lyase, which participates in the fumarate metabolic process, was also 1.46 -fold more abundant in the 1-h-old female An. gambiae S reared under the "ods" conditions, but was slightly less abundant in the M molecular form. These higher amounts of enzymes involved in energetic pathways could suggest increased energetic needs for female mosquitoes, more particularly at the onset of the dry season. Several studies have demonstrated the prominent importance of carbohydrate oxidisation, and elevated TCA cycle activity in dipterans to fuel wing muscles during flight (Briegel, 2003). Proline has been demonstrated as an essential metabolite used to fuel dipteran's flight, as in Aedes aegypti (Diptera: Culicidae) (Scaraffia and Wells, 2003). According to these authors, proline, which we found in higher amounts in 24-h-old An. gambiae S reared under "ods" conditions, is transported from the fat body to flight muscles to be converted into $\alpha$ ketoglutarate. It then fuels the TCA cycle, and produces the energetic substrate necessary for striated muscle contractions. Recently,Adamou et al. (2011) and Lehmann et al. (2014) suggest that specimens of An. gambiae $\mathrm{S}$ might migrate at the onset of the dry season towards more suitable areas. Our data could support this idea, although further studies are required to examine (i) the metabolic rate of these mosquitoes when exposed to contrasting environmental parameters (Huestis et al., 2011, 2012), and (ii) if differences in the expression of the TCA cycle enzymes sustain different flying activity patterns between the two molecular forms, particularly at the onset of the dry season.

\section{Conclusion}

Ecological divergence and contrasted population dynamics in the $\mathrm{M}$ and S forms of An. gambiae in Sahelian areas of sub-Saharan Africa suggest that the two species adopted different dry-season survival strategies to overcome the detrimental effects of climatic seasonality (Adamou et al., 2011; Lehmann et al., 2010, 2014). Supporting our expectations, the present study provides evidence that developmental acclimation contributed to alternating phenotypes between rainy and dry season in freshly emerged mosquitoes, and these phenotypes differed between the two molecular forms. In particular we found evidence that these alternating phenotypes enhance tolerance and resistance to desiccation in both forms and are accompanied by several changes in physiological and biochemical processes, including an increase in the biochemical hydrophobicity of the cuticle in the $\mathrm{M}$ form and increased demand of energetic substrate in the $\mathrm{S}$ form. Further research on the metabolic pathways and their underlying regulatory mechanisms that are involved in preparing individual mosquitoes for the adverse dry season conditions are needed to better understand population dynamic observations conducted at the population level. Combining experimental studies with high-throughput methods such as proteomics and metabolomics holds much promise towards elucidating the physiological mechanisms underlying dry season tolerance in these tropical mosquitoes. Moreover, such studies will pave the way for the development and successful implementation of innovative vector control strategies that target mosquito populations during unsuitable periods when they are most amenable to control. 


\section{Footnotes}

2Based on bionomical and genetic data, the two forms were recently elevated to species, and named An. coluzzii and An. gambiae, respectively (Coetzee et al., 2013). Meanwhile, a consensus has not yet been reached on the species status of these incipient taxa (see Lee et al., 2013), and therefore we continue to refer to the $\mathrm{M}$ and $\mathrm{S}$ nomenclature in this paper.

\section{Acknowledgements}

This research was supported by the Agence Nationale de la Recherche (France) through grant ANR-o8-MIEN-oo6 to F.S. The authors would like to thank Moundai Tchonfienet, Sougrinoma Zoungrana and Boubakar Nikiema (IRSS, Bobo-Dioulasso) for their help in mosquito rearing and sample preparation. The mass spectrometry proteomics data have been deposited in the ProteomeXchange Consortium (http://proteomecentral.proteomexchange.org) via the PRIDE partner repository with the dataset identifier PXDooo294. We would like to thank the PRIDE team for their support and two anonymous referees for their helpful comments on earlier versions of this paper. Finally we thank Megan Meuti (Ohio state university) for critical reading of the paper.

\section{Appendix A. Supplementary data}

Supplementary data associated with this article can be found, in the online version, at http://dx.doi.org/10.1016/i.jinsphys.2014.07.003

\section{References}

Adamou A., Dao A., Timbine S., Kassogué Y., Yaro A.S., Diallo M., Traoré S.F.,Huestis D.L. a nd Lehmann T., The contribution of aestivating mosquitoes to the persistence of Anopheles gambiae in the Sahel, Malaria J. 10, 2011, 151,DOI: 10.1186/1475-2875$10-151$

Andersen S.O., Biochemistry of insect cuticle, Annu. Rev. Entomol. 24, 1979,2959, DOI: 10.1146/annurev.en.24.010179.000333

Baldet T., Diabaté A. and Guiguemdé T.R., Malaria transmission in 1999 in the rice field are of the Kou Valley (Bama), (Burkina Faso), Santé 13, 2003, 55-60.

Behmer S.T. and Joern A., Dietary selection by the generalist grasshopperPhoetaliotes nebrascensis (Orthoptera: Acrididae), Funct. Ecol. 7, 1993,522-527.

Benjamini Y. and Hochberg Y., Controlling the false discovery rate: a practical and powerful approach to multiple testing, J. R. Stat. Soc. Ser. B 57, 1995,289-300.

Benoit J.B., Patrick K.R., Desai K., Hardesty J.J., Krause T.B. and Denlinger D.L.,Repeated bouts of dehydration deplete nutrient reserves and reduce egg production in the mosquito Culex pipiens, J. Exp. Biol. 213, 2010,2763 2769, DOI: $10.1242 /$ jeb.044883

Briegel H., Physiological bases of mosquito ecology, J. Vector Ecol. 28, 2003,1-11. Brunet P.C., Tyrosine metabolism in insects, Ann. N.Y. Acad. Sci. 10o, 1963,1020-1034.

Bullard B. and Pastore A., Regulating the contraction of insect flight muscle, J. Muscle Res. Cell Motill. 32, 2011, 303-313, DOI: 10.1007/s10974-011-9278-1.

Cassone B.J., Molloy M.J., Cheng C., Tan J.C., Hahn M.W. and Besansky N.J.,Divergent transcriptional response to thermal stress by Anopheles gambiaelarvae carrying alternative arrangements of inversion $2 \mathrm{La}$, Mol. Ecol. 2o, 2011, 25672580, DOI: $10.1111 / \mathrm{j} \cdot 1365-294$ X.2011.05114.x.

Chown S.L. and Nicolson S., Insect Physiological Ecology: Mechanisms and Patterns, 2004, Oxford University Press; Oxford

Chown S.L., Sørensen J.G. and Terblanche J.S., Water loss in insects: an environmental change perspective, J. Insect Physiol. 57, 2011, 1070-1084.

Coetzee M., Hunt R.H., Wilkerson R., della Torre A., Coulibaly M.B. and BesanskyN.J., Anopheles coluzzii and Anopheles gambiae complex, Zootaxa 3619 (2), 2013, 246-274.

Colinet H., Renault D., Charoy-Guével B. and Com E., Metabolic and proteomic profiling of diapause in the aphid parasitoid Praon volucre, PLoS One 7, 2012, e32606, DOI: 10.1371/journal.pone.0032606.

Colinet H., Overgaard J., Com E. and Sørensen J.G., Proteomic profiling of thermal acclimation in Drosophila melanogaster, Insect Biochem. Mol. Biol. 43, 2013, 352365, DOI: 10.1016/j.ibmb.2013.01.006.

Crawley M.J., The R Book, 2007, John Wiley \& Sons.

Crowe J., Anhydrobiosis, Annu. Rev. Physiol. 54, 1992, 579-599.

R Development Core Team, R: A Language and Environment for Statistical Computing, 2008, R Foundation for Statistical Computing; Vienna. ISBN: 3-90005107-0, <http://www.R-project.org>.

Elnitsky M.A., Hayward S.A.L., Rinehart J.P., Denlinger D.L. and Lee R.E.,Cryoprotective dehydration and the resistance to inoculative freezing in the Antarctic midge, Belgica dehydration and the resistance to inoculative
antarctica, J. Exp. Biol. 211, 2008, 524-530.

Fontenille D. and Simard F., Unravelling complexities in human malaria transmission dynamics in Africa through a comprehensive knowledge of vector populations, Comp. dynamics in Africa through a comprehensive knowle.
Immunol. Microbiol. Infect. Dis. 27, 2004,357-375.

Fontenille D., Lochouarn L., Diagne N., Sokhna C., Lemasson J.J., Diatta M.,Konate L., Faye F., Rogier C. and Trape J.F., High annual and seasonal variations in malaria transmission by anophelines and vector species composition in Dielmo, a
Fouet C., Gray E., Besansky N.J. and Costantini C., Adaptation to aridity in the malaria mosquito Anopheles gambiae: chromosomal inversion polymorphism and body size

One 7 (4), 2012, e34841, DOI: 10.1371/journal.pone.0034841.

Gibbs A.G., Chippindale A.K. and Rose M.R., Physiological mechanisms of evolved desiccation resistance in Drosophila melanogaster, J. Exp. Biol. 200, 1997,18211832.

Gibbs A.G., Louie A.K. and Ayala J.A., Effects of temperature on cuticular lipids and water balance in a desert Drosophila: is thermal acclimation beneficial?,J. Exp. Biol. 201, 1998, 71-80.

Gibbs A.G., Fukuzato F. and Matzkin L.M., Evolution of water conservation mechanisms in Drosophila, J. Exp. Biol. 206, 2003, 1183-1192,DOI: 10.1242/jeb.00233.

Gimonneau G., Pombi M., Choisy M., Morand S., Dabiré R.K. and Simard F.,Larval habitat segregation between the molecular forms of the mosquitoAnopheles gambiae in a rice field area of Burkina Faso, West Africa, Med. Vet. Entomol. 26, 2012, 917, DOI: 10.1111/j.1365-2915.2011.00957.x.

Goldspink G., Scutt A., Loughna P.T., Wells D.J., Jaenicke T. and Gerlach G.F.,Gene expression in skeletal muscle in response to stretch and force generation, Am. $J$. Physiol. 262, 1992, R356-R 363 .

Goltsev Y., Rezende G.L., Vranizan K., Lanzaro G., Valle D. and Levine M.,Developmental and evolutionary basis for drought tolerance of theAnopheles gambiae embryo, Dev. and evolutionary basis for drought tolerance of the Anopheles $g$
Biol. 330, 2009, 462-470,DOI: 10.1016/j.ydbio.2009.02.038.

Gray E., Kyle M., Rocca A.C., Costantini C. and Besansky N.J., Inversion 2La is associated with enhanced desiccation resistance in Anopheles gambiae,Malaria $J .8$ (1), 2009, 215, DOI: 10.1186/1475-2875-8-215.

Hadley N.F., Water Relations of Terrestrial Arthropods, 1994, Academic Press;San Diego.

Hoffmann A.A. and Harshman L.G., Desiccation and starvation resistance in Drosophila: patterns of variation at the species, population and intrapopulation patterns of variation at the species, population and intrapopulation
levels, Heredity 83, 1999, 637-643, DOI: 10.1046/j.1365-2540.1999.00649.x.

Hoffmann A.A. and Parsons P.A., Direct and correlated responses to selection for desiccation resistance: a comparison of Drosophila melanogaster and D. simulans, J. Evol Biol. 6, 1993, 643-657, DOI: 10.1046/j.1420-9101.1993.6050643.x.

Holmes K.C., Steric blocking mechanism explains stretch activation in insect flight muscle, Proc. Natl. Acad. Sci. U.S.A. 108, 2011, 7-8,DOI: 10.1073/pnas.1017429108.

Holstein M.H., Biology of Anopheles gambiae: Research in French West Africa,1954, World Health Organization.

Huestis D.L., Yaro A.L., Traoré A.I., Adamou A., Kassogué Y., Diallo M., TimbinéS., Dao A. a nd Lehmann T., Variation in metabolic rate of Anopheles gambiae and $A$. arabiensis in a sahelian village, J. Exp. Biol. 214, 2011,23452353, DOI: $10.1242 /$ jeb.054668.

Huestis D.L., Yaro A.S., Traoré A.I., Dieter K.L., Nwagbara J.I., Bowie A.C.,Adamou A.Y., Dia llo M., Timbiné S., Dao A. and Lehmann T., Seasonal variation in metabolic rate, flight activity and body size of Anopheles gambiae in the Sahel, J. Exp. Biol. 215, 2012, 2013-2021,DOI: 10.1242/jeb.069468

Iconomidou V.A., Willis J.H. and Hamodrakas S.J., Unique features of the structural model of "hard" cuticle proteins: implications for chitin-protein interactions and cross-
linking in cuticle, Insect Biochem. Mol. Biol. 35, 2005, 553-560.

Im A.R., Park Y., Sim J.S., Zhang Z., Liu Z., Linhardt R.J. and Kim Y.S.,Glycosaminoglycans from earthworms (Eisenia andrei), Glycoconjugate J. 27, 2010, 249-257.

Koenraadt C.J.M., Paaijmans K.P., Githeko A.K., Knols B.G.J. and Takken W., Egg hatching, arval movement and larval survival of the malaria vectorAnopheles gambiae in

ig M., Agrawal O.P., Schenkel H. and Scheller K., Incorporation of calliphorin into the cuticle of the developing blowfly, Calliphora vicina, Roux's Arch. Dev. Biol. 195, 1986, 296-301.

Kültz D., Molecular and evolutionary basis of the cellular stress response, Annu. Rev. Physiol. 67, 2005, 225-257. 
Lee Y., Marsden C.D., Norris L.C., Collier T.C., Main B.J., Fofana A., Cornel A.J.and Lanzaro G.C., Spatiotemporal dynamics of gene flow and hybrid fitness between the M and S forms of the malaria mosquito, Anopheles gambiae,Proc. Natl. Acad. Sci. 110, 2013, 19854-19859.

Lehmann T., Dao A., Adamou A., Kassogue Y., Diallo M., Sékou T. and CoscaronArias C., Aestivation of the African malaria mosquito, Anopheles gambiae in the Sahel, Am. J. Trop. Med. Hyg. 83, 2010, 601-606,DOI: 10.4269/ajtmh.2010.090779

Lehmann T., Dao A., Yaro A.S., Diallo M., Timbiné S., Huestis D.L., Adamou A.,Kassogué Y. and Traoré A.I., Seasonal variation in spatial distributions of Anopheles gambiae; in Sahelian village: evidence for aestivation, J. Med. Entomol. 51, 2014, 2738, DOI: $10.1603 /$ ME13094

Lemasson J.J., Fontenille D., Lochouarn L., Dia I., Simard F., Ba K., Diop A., DiattaM. and M olez J.F., Comparison of behavior and vector efficiency ofAnopheles gambiae and An. arabiensis (Diptera:Culicidae) in Barkedji, a Sahelian area of Senegal, J. Med.
Entomol. 34, 1997, 396-403.

Li A. and Denlinger D.L., Pupal cuticle protein is abundant during early adult diapause in the

mosquito Culex pipiens, J. Med. Entomol. 46, 2009,1382-1386.
Marron M.T., Markow T.A., Kain K.J. and Gibbs A.G., Effects of starvation and desiccation on energy metabolism in desert and mesic Drosophila, J. Insect Physiol. 49, 2003, 261-270.

Minakawa N., Githure J.I., Beier J.C. and Yan G., Anopheline mosquito survival strategie during the dry period in Western Kenya, J. Med. Entomol. 38, 2001, 388-392.

Mouline K., Mamai W., Agnew P., Tchonfienet M., Brengues C., Dabiré R., RobertV. and Sim ard F., Physiology and development of the $\mathrm{M}$ and $\mathrm{S}$ molecular forms of Anopheles 454, DOI: 10.1111/j.1365-2915.2012.01018.x.

Muir L. and Lee Y.C., Structures of the D-galactose oligosaccharides from earthworm cuticle collagen, J. Biol. Chem. 244, 1969, 2343-2349.

Neville A.C., Biology of the Arthropod Cuticle, 1975, Springer-Verlag; Berlin \& New York.

Omer S.M. and Cloudsley-Thompson J.L., Survival of female Anopheles gambiaeGile through a 9-month dry season in Sudan, Bull. World Health Organ. 42, 1970, 319330

Quinlan M.C. and Gibbs A.G., Discontinuous gas exchange in insects, Respir. Physiol. Neurobiol. 154, 2006, 18-29.

Renault H., Roussel V., Amrani A.E., Arzel M., Renault D., Bouchereau A. andDeleu C., The Arabidopsis pop2-1 mutant reveals the involvement of GABA transaminase in salt

Rocca K.A.C., Gray E.M., Costantini C. and Besansky N.J., 2La chromosomal inversion enhances thermal tolerance of Anopheles gambiae larvae, Malaria

osenfeld J., Capdevielle J., Guillemot J.C. and Ferrara P., In-gel digestion of proteins for internal sequence analysis after one- or two-dimensional gel electrophoresis, Anal. Biochem. 203, 1992, 173-179.
Santolamazza F., Mancini E., Simard F., Qi Y., Tu Z. and della Torre A., Insertion polymorphisms of SINE20O retrotransposons within speciation islands of Anopheles gambiae molecular forms, Malaria J. 7, 2008, 163,DOI: 10.1186/1475-2875-7-163.

Scaraffia P.Y. and Wells M.A., Proline can be utilized as an energy substrate during flight of Aedes aegypti females, J. Insect Physiol. 49, 2003,591-601.

Schmidt-Nielsen K., Animal Physiology: Adaptation and Environment, fourth ed.,1990, Cambridge University Press; Cambridge.

Simard F., Lehmann T., Lemasson J.J., Diatta M. and Fontenille D., Persistence ofAnopheles arabiensis during the severe dry season conditions in Senegal: an indirect approach using microsatellite

tankiewicz B., Van

Bergen P.F., Duncan I.J., Carter J.F., Briggs D.E.G. andEvershed R.P., Recognition of chitin and proteins in invertebrate cuticles using analytical pyrolysis/gas chromatography and pyrolysis/gas chromatography/mass spectrometry, Rapid Commun. Mass Spectrom. 10, 1996, 1747-1757.

Taylor C.E., Toure Y.T., Coluzzi M. and Petrarca V., Effective population size and persistence of Anopheles arabiensis during the dry season in West Africa,Med. Vet. Entomol. 7, 1993, 351-357, DOI: 10.1111/j.1365-2915.1993.tboo704.x.

Telfer W.H. and Kunkel J.G., The function and evolution of insect storage hexamers, Annu. Rev. Entomol. 36, 1991, 205-228.

Thorat L.J., Gaikwad S.M. and Nath B.B., Trehalose as an indicator of desiccation stress in Drosophila melanogaster larvae: a potential marker of anhydrobiosis, Bioch Biophys. Res. Commun 419, 2012, 638-642,DOI: 10.1016/j.bbrc.2012.02.065

Touré Y.T., Petrarca V., Traoré S.F., Coulibaly A., Maiga H.M., Sankaré O., SowM., Di Deco M.A. and Coluzzi M., The distribution and inversion polymorphism of Deco M.A. and Coluzzi M., The distribution and inversion polymorphism of
chromosomally recognized taxa of the Anopheles gambiae complex in Mali, West Africa, Parassitologia 40, 1998, 477-511.

True J.R., Insect melanism: the molecules matter, Trends Ecol. Evol. 18, 2003,640647, DOI: $10.1016 /$ j.tree.2003.09.006.

Truman J.W. and Riddiford L.M., The origins of insect metamorphosis,Nature 401, 2000, 447-452.

Williams D.F., Vander Meer R.K. and Lofgren C.S., Diet-induced nonmelanized cuticle in workers of the imported fire ant Solenopsis invicta Buren, Arch. Insect Biochem. Physiol. 4, 1987, 251-259,DOI: 10.1002/arch.940040403.

Willis J.H., Iconomidou V.A., Smith R.F. and Hamodrakas S.J., Cuticular proteins,In: Gilbert L.I., Iatrou K. and Gill S.S., (Eds.), Comprehensive Molecula Insect Science, 2005, Elsevier; Oxford, 79-110.

Withers P.C., Comparative Animal Physiology, 1992, Saunders College; Orlando.

Yancey P.H., Organic osmolytes as compatible, metabolic and counteracting cytoprotectant in high osmolarity and other stresses, J. Exp. Biol. 208, 2005, 28192830, DOI: $10.1242 /$ jeb.01730.

Zachariassen K.E., The water conserving physiological compromise of desert insects, Eur.J. Entomol. 93, 1996, 359-367. 